\title{
An Automated Detection Methodology for Dry Well-Mixed Layers ${ }^{\mathscr{A}}$
}

\author{
STEPHEN D. NiCHOLLS \\ Joint Center for Earth Systems Technology, University of Maryland, Baltimore County, \\ Baltimore, and Mesoscale Atmospheric Processes Laboratory, NASA Goddard \\ Space Flight Center, Greenbelt, Maryland
}

KAREN I. MOHR

Laboratory for Atmospheres, Earth Sciences Division, NASA Goddard Space Flight Center, Greenbelt, Maryland

(Manuscript received 23 August 2018, in final form 28 January 2019)

\begin{abstract}
The intense surface heating over arid land surfaces produces dry well-mixed layers (WML) via dry convection. These layers are characterized by nearly constant potential temperature and low, nearly constant water vapor mixing ratio. To further the study of dry WMLs, we created a detection methodology and supporting software to automate the identification and characterization of dry WMLs from multiple data sources including rawinsondes, remote sensing platforms, and model products. The software is a modular code written in Python, an open-source language. Radiosondes from a network of synoptic stations in North Africa were used to develop and test the WML detection process. The detection involves an iterative decision tree that ingests a vertical profile from an input data file, performs a quality check for sufficient data density, and then searches upward through the column for successive points where the simultaneous changes in water vapor mixing ratio and potential temperature are less than the specified maxima. If points in the vertical profile meet the dry WML identification criteria, statistics are generated detailing the characteristics of each layer in the profile. At the end of the vertical profile analysis, there is an option to plot analyzed profiles in a variety of file formats. Initial results show that the detection methodology can be successfully applied across a wide variety of input data and North African environments and for all seasons. It is sensitive enough to identify dry WMLs from other types of isentropic phenomena such as subsidence layers and distinguish the current day's dry WML from previous days.
\end{abstract}

\section{Introduction}

Intense daytime surface heating over arid land surfaces such as deserts produces dry convective mixing in the boundary layer. In the absence of external influences capable of generating significant mechanical turbulence such as fronts or thunderstorm outflow, local dry convection can produce a deep, well-mixed, nearly isentropic boundary layer that later becomes a dry well-mixed residual layer in the evening (Bounoua and Krishnamurti 1991; Gamo 1996; Warner 2004; Messager et al. 2010; Garcia-Carreras et al. 2015).

\footnotetext{
Supplemental information related to this paper is available at the Journals Online website: https://doi.org/10.1175/JTECH-D-180149.s1.

Corresponding author: Stephen D. Nicholls, stephen.d.nicholls@ nasa.gov
}

These dry well-mixed layers (WMLs) can retain their unique midtropospheric thermal and humidity structure for several days and be transported thousands of kilometers downstream (Carlson and Prospero 1972; Prospero and Carlson 1981; Zhang and Pennington 2004; Cuesta et al. 2008, 2009). In general, low- and midlevel dry WMLs are detrimental to moist convection due to water loading and dry entrainment into rising moist eddies (Lucas et al. 2000; Wang and Sobel 2012; Takemi 2014; Honda and Kawano 2015). However, for environments with strong, low-level moist convergence and shear, a midlevel dry WML can indirectly promote stronger updrafts and deep, often intense convection initially at the expense of weaker moist eddies. When the first weak buoyant plumes attempt to traverse an elevated, dry WML, dry air entrainment, water loading, and evaporative cooling will eliminate the buoyancy of those rising eddies and promote the formation of downdrafts and low-level 
cold pools. Given sufficient low-level moist convergence and shear, feedbacks can develop in which these cold pools foster the formation of larger (1-km scale), stronger $\left(>10 \mathrm{~m} \mathrm{~s}^{-1}\right)$ moist eddies more impervious to dry air entrainment and water loading. The undiluted ascent within the core of wide, strong eddies makes it possible for them to grow to the level of free convection, access midlevel CAPE, and release built-up instability (Carr and Millard 1985; Peckham et al. 2004; James and Markowski 2010; Trier et al. 2015). The transport of midlevel dry WMLs from upstream deserts overrunning low-level moist airstreams has long been observed to coincide with severe local storm development in North America (e.g., Carlson and Ludlam 1968; Schaefer 1974; Carlson et al. 1983; Benjamin and Carlson 1986; Lanicci et al. 1987). Midlevel dry WMLs are also associated with the potential for intense convection in Asia (e.g., Medina et al. 2010; Romatschke and Jr. 2011; Yamane et al. 2013; Liu and Liu 2018), coastal Australia (Allen and Karoly 2014; Grundstein et al. 2017), central Europe (e.g., Bissolli et al. 2007; Graf et al. 2011; Matsangouras et al. 2014; Púčik et al. 2015), South America (Romatschke et al. 2010; Rasmussen and Houze 2011; Zuluaga and Houze 2015), and West Africa (e.g., Roca et al. 2005; Nicholls and Mohr 2010; Vizy and Cook 2018).

The dry WML is an important element of dryland boundary layer meteorology as well as to the convective environments of more humid regions. Our research goal was to develop a quantitative, efficient, and automated detection algorithm to identify and characterize dry WMLs within the vertical column. The first step was to define what a dry WML is so that it could be coded into a software algorithm. Starting from the working hypothesis that a dry WML is generated by dry convection over arid land surfaces and has a distinctive thermodynamic structure, we adopt the following definition of a dry WML and analysis principles.

\section{Definition of dry WML}

A dry WML is a layer of nearly constant potential temperature and low, nearly constant water vapor mixing ratio, capped by an inversion, with a positive vertical gradient of relative humidity.

- The WMLs result primarily from dry convective mixing due to intense surface heating.

- The magnitude of the allowable water vapor mixing ratio is determined a priori from analysis of surface observations in the area of interest.

- The analysis covers the lower to midtroposphere.

The use of the acronym "WML" in this paper will imply a dry WML, one with a water vapor mixing ratio below the a priori empirically determined allowable level. Any regionally or temporally extensive study of WMLs would require the inspection and analysis of multiple simultaneous temperature and humidity profiles from various available data sources. While radiosonde and rawinsonde observations (raobs) have the best vertical resolution and accuracy, temperature and humidity profiles can also be extracted from model reanalysis datasets (e.g., Dee et al. 2011; Gelaro et al. 2017) or retrieved from spaceborne sounders such as the Atmospheric Infrared Sounder (AIRS), the Advanced Microwave Sounding Unit (AMSU), or the Geostationary Operational Environmental Satellite (GOES) sounder (Ma et al. 1999; Aumann et al. 2003; Weng et al. 2003; Menzel et al. 2018). As compared to raobs these alternative inputs have the advantage of improved spatial coverage and, in some cases, improved temporal resolution. Whether the analysis source is ground observations, remote sensing products, or model output, manual inspection and analysis of hundreds, perhaps thousands, of profiles would be prohibitively time consuming and difficult to quality control. To make an extensive and statistically consistent study of WMLs possible, we adapted our detection methodology to accept inputs from a variety of data sources including remote sensing and model products.

In this paper, we describe the WML detection methodology and show examples of analyzed WMLs in raobs and other data inputs from North Africa. In addition to containing the Sahara Desert, North Africa has several important features making it a useful study area, including raob sites with long observational records, multiple land surface types, and multiple dynamical influences such as synoptic waves, large-scale subsidence, moist monsoon inflow, and marine inversion layers that challenged us in creating a flexible and accurate detection methodology. Because the software is written in Python, it is open source, readably transferable, and usable by potential users. Here we demonstrate its utility and its potential application in North African meteorological process studies and possibly in other arid regions.

\section{Background}

\section{a. Study area description}

Our study area in North Africa encompasses $0^{\circ}-37^{\circ} \mathrm{N}$, $18^{\circ} \mathrm{W}-45^{\circ} \mathrm{E}$, containing all of the Sahara Desert. Figure 1 is a map of the 53 synoptic stations used in our analysis and the Bailey's ecoregion provinces of North Africa (Bailey 2004, 2014). These provinces blend the analysis of climate and actual and potential dominant vegetation 


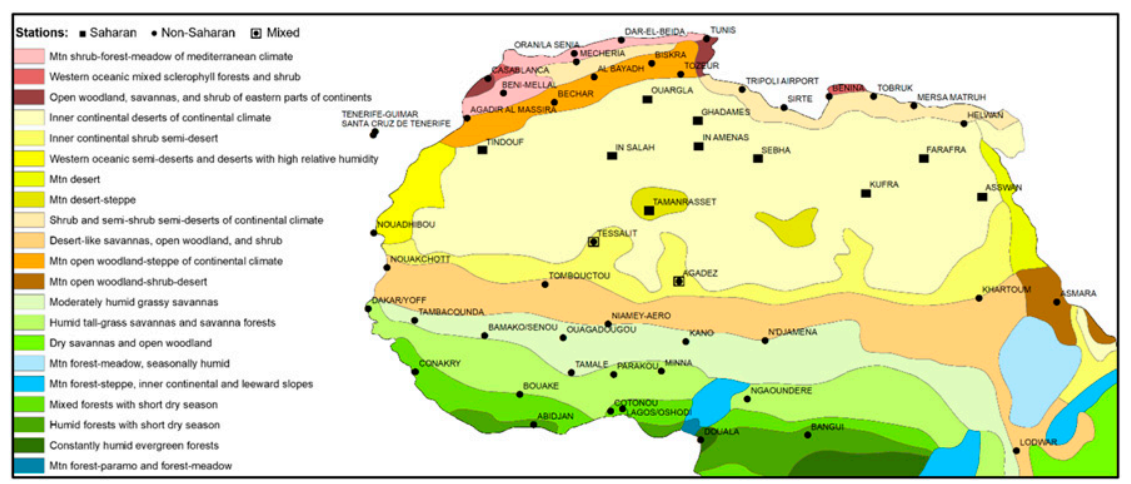

FIG. 1. A map of the Bailey's ecoregion provinces for North Africa with the raob stations indicated by black squares (Saharan stations), black dots (non-Saharan stations), and black open squares around dots (mixed stations that function as Saharan stations during most but not all months). The color scheme refers to the ecoregion division and vegetation provinces within them ("Mtn" applies to mountain ecoregions). Red shades apply to the Mediterranean division, yellow to the tropical/subtropical desert division, and orange to the tropical/subtropical steppe division. Greens and blues apply to the savanna division (lighter shades) and rain forest division (darker shades).

types to delineate relatively stable and continuous ecosystem boundaries. The yellow shades in Fig. 1 define the ecoregion provinces in the Sahara Desert. The mountain provinces (west to east) cover the Hoggar, Tibesti, and Red Sea Hills ranges. The 10 synoptic stations marked with a black square denote inner Saharan stations, which are unaffected by coastal processes such as marine layers. During July and August, the profiles at the two "mixed" stations (black circle and square outline), Tessalit and Agadez, have a moist monsoon layer, reflecting their location at the far northern edge of the West African monsoon (Lélé and Lamb 2010). The 41 remaining stations (black circles) on the coasts or in Mediterranean (red shades), steppe (orange), savanna (light greens and blues), and rain forest (dark greens and blues) divisions are defined as non-Saharan because they are affected by coastal processes or are outside the Sahara Desert.

All references to seasons in North Africa henceforth imply boreal seasons. References to the West African monsoon imply a period from late April to mid- to late November when the stations south of Tamanrasset $\left(22^{\circ} \mathrm{N}\right)$ receive most of their annual precipitation due to a low-level, moist southwesterly inflow from the Gulf of Guinea (review in Fitzpatrick et al. 2015). Along the Mediterranean coast, the wet season is in the winter, primarily from intruding transient extratropical waves and Atlantic depressions (Knippertz 2003; Knippertz et al. 2003; Born et al. 2010). The ecoregion gradients in Fig. 1 from desert to steppe to savanna/woodland/ meadow to rain forest provinces usefully delineate a decreasing expected occurrence of WMLs generated in the local boundary layer by dry convection due to intense surface heating (Warner 2004; Nicholson 2011). Even at Saharan stations, it can be difficult to separate the signal from dry convection from dry intrusions from transient extratropical or tropical waves or from regional subsidence (Roca et al. 2005; Vizy and Cook 2009; Raveh-Rubin 2017). Despite the challenge posed by multiple possible larger-scale dynamical influences on local profiles around North Africa (e.g., Nicholson 1996; Camberlin 2009; Fink 2017), we developed our detection methodology using temperature and humidity profiles from every month of the year and using all stations in Fig. 1.

\section{b. Data description}

The foundation of this work was raobs from 53 North African stations (Fig. 1) to build the detection and plotting modules and to validate analyses performed with model and remote sensing inputs. We obtained raob data from the Integrated Global Radiosonde Archive (IGRA), version 2, at NOAA's National Centers for Environmental Information (NCEI). The IGRA has radiosonde, rawinsonde, and pilot balloon data in text format from stations around the world, with several hundred stations having records that extend back to the early twentieth century. While the data records in IGRA are rigorously quality controlled for implausible values and internal inconsistencies, individual soundings are of varying data densities, depending on the station's ability to report significant and mandatory levels and those in between (Durre et al. 2006). The earliest North African raobs used in this study are from 1948. Many of the stations have temporally noncontinuous records, although for the purposes of this work, temporal 
continuity was not important. All North African raobs that had temperature and humidity values at the mandatory levels from the station surface up to and including $500 \mathrm{hPa}$ were defined as "useful." Figure 2 contains maps of the useful observations available at each North African station since (Fig. 2a) 1948 and (Fig. 2b) 2003. Some of the stations, particularly in Libya, Algeria, and Nigeria, stopped reporting before 2003, but had enough quality older observations to be included in the counts. Applying our "useful" observation criteria to all raob launches since 1948, only 35\% (450000 observations) were useful for methodological development and testing.

After we derived a robust detection methodology for analysis of raobs, we applied it to analyzing temperature and humidity products from the cross-track scanning IR and microwave sounders, AIRS and AMSU, on NASA's polar-orbiting Aqua satellite (Parkinson 2003). The midday Aqua overpasses over North Africa coincide with the development of deep daytime boundary layers over arid surfaces (Marsham et al. 2013; Garcia-Carreras et al. 2015). The AIRS is an infrared spectrometer/radiometer that covers the 3.7-15.4- $\mu \mathrm{m}$ spectral range with 2378 spectral channels, and AMSU is a 15-channel microwave radiometer operating between 23 and $89 \mathrm{GHz}$ (Aumann et al. 2003). Our work used the version 6 sensor-resolution, ungridded level 2 (L2) temperature and humidity support products at $50 \mathrm{~km} \times 50 \mathrm{~km}$ horizontal resolution, and 28 standard pressure levels plus intermediate pressure levels for a total of 100 pressure levels across a $1650-\mathrm{km}$ swath. Although there are twice-daily observations over Africa, this work involved only the daytime passes. The version 6 collection of L2 products include AIRS + AMSU combined retrievals (AIRX2SUP) and an AIRS-only retrieval (AIRS2SUP) that, compared to previous versions, significantly improve cloud clearing and the retrieval of surface and cloud parameters (Susskind et al. 2012, 2014; Stubenrauch et al. 2017). Vergados et al. (2018) evaluated global tropospheric specific humidity maps among multiple gridded humidity datasets, including one derived from AIRS + AMSU, finding that the climatologies varied by less than $15 \%$ depending on region and pressure level, with AIRS + AMSU ranked as the driest of the datasets.

We also used profiles from two reanalysis datasets in this study, 1) the European Centre for Medium-Range Weather Forecasts (ECMWF) interim reanalysis (ERAInterim, hereafter ERA-I) at 6-h and $0.75^{\circ} \times 0.75^{\circ} \times 60$ model levels (Dee et al. 2011); 2) NASA Modern-Era Retrospective Analysis for Research and Applications, version 2 (MERRA-2), at 1 -h and $0.625^{\circ} \times 0.50^{\circ} \times$ 72 model levels (Gelaro et al. 2017). Both of these
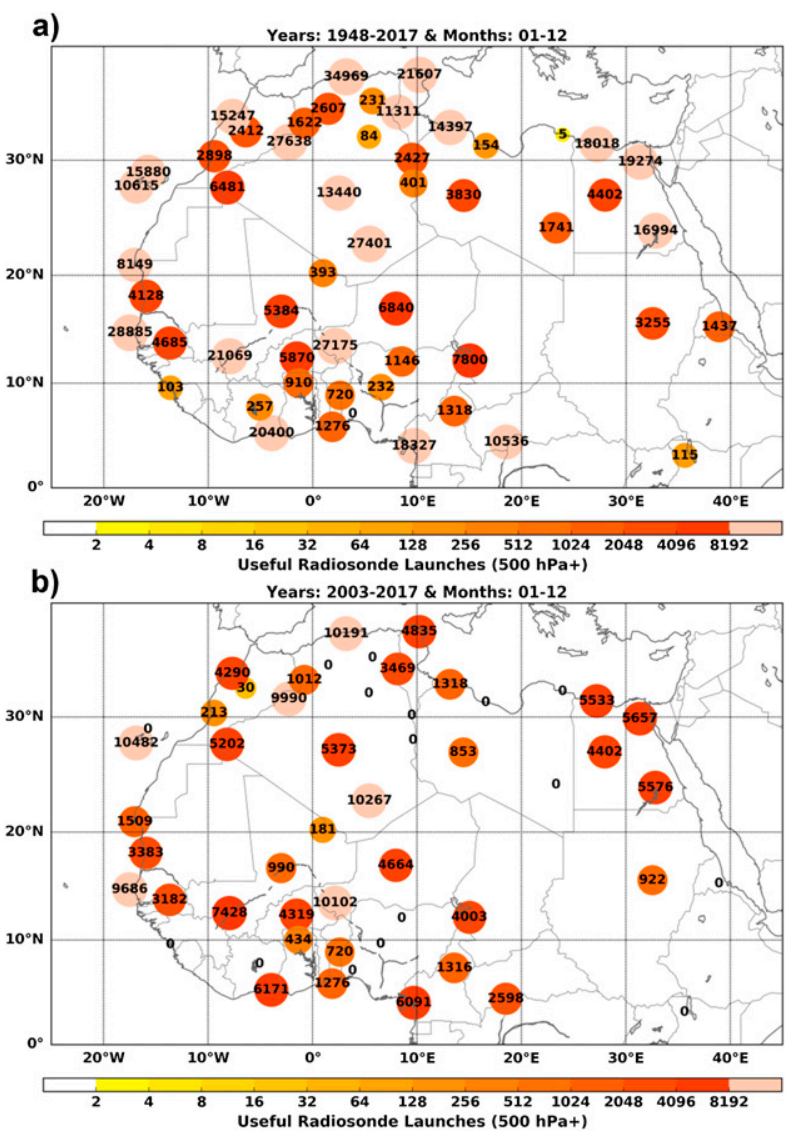

FIG. 2. Maps of the North African stations with the number of useful radiosonde launches resulting in a raob that could be used for algorithm development. (a) Useful launches since the earliest observation in the IGRA, 1948. (b) Useful launches since 2003, the first full year of operations of the Aqua satellite mission. The use of input from Aqua sounders and from model reanalysis starts with 2003 , although model reanalysis can go further back in time. The stations marked with zero are stations that do not have observations during the Aqua era.

modeling centers run data assimilation systems that incorporate AIRS and other atmospheric sounder radiances as well as observations from the operational raob network. Because global operational modeling systems are run at resolutions too coarse $(>10 \mathrm{~km})$ to resolve convective-scale phenomena explicitly in North Africa, multiple authors have demonstrated that the assimilation of raobs strongly influences forecasted atmospheric state variables to an approximate diameter of $300-500 \mathrm{~km}$ around the synoptic station, depending on variable, model resolution, and model physics (AgustíPanareda et al. 2010; Fink et al. 2011; Roberts et al. 2015). Because validation of remote sensing and reanalysis inputs is grounded at past and present operational synoptic stations, our examples of reanalysis performance should be considered the best possible for 
those datasets, degrading with distance from synoptic stations.

Because major modeling centers assimilate radiances from the AIRS and AMSU sensors (e.g., Gelaro et al. 2017), it is important to point out the independence of version 6 AIRS and AIRS + AMSU temperature and humidity products from model products, such as MERRA-2. The AIRS and AIRS + AMSU products are derived from a physical retrieval system using a neural network first guess. The neural network consists of interconnected nonlinear function approximators trained to infer a statistical relationship between inputs (AIRS and AMSU radiances) and outputs (temperature and humidity profiles) without requiring direct knowledge of the functional input/output relationship (Blackwell 2005, 2012). For a given version of AIRS retrieved products, the neural network was trained once from collocated model analysis fields over many different months and years. The historically trained neural network coefficients are then used in all subsequent operational retrievals so that each day's temperature and humidity profiles are independent of any analysis fields from any modeling center (Blackwell 2012; Milstein and Blackwell 2016). Given a first guess, the AIRS retrieval performs a physically based cloudclearing step estimate of what would be the cloud-free infrared radiance spectrum using nine single field-ofview AIRS observations in a $3 \times 3$ IR field of regard coinciding with an AMSU footprint and, when available, the microwave measurements in same position (Cho and Staelin 2006; Susskind et al. 2014). The AIRS retrieval methodology finds iterative solutions, starting from the first guess, to the radiative transfer equations on a field-of-regard basis that best match the derived cloud-cleared radiances determined for that field of regard. The combination of the AIRS neural network-based first guess and physically based cloud-clearing methodology makes robust, qualitycontrolled AIRS and AIRS + AMSU retrievals in almost all cloud conditions, including retrievals above overcast conditions and over storms (Blackwell and Milstein 2014; Milstein and Blackwell 2016; Reale et al. 2018).

\section{WML detection methodology}

\section{a. Governing reference values}

In the development phase, we made first guesses of the parameters defining the analysis column and what defines "dry," the maximum allowable water vapor mixing ratio $w$, and "nearly constant," the simultaneous maximum allowable change in potential temperature $\theta$ and maximum allowable change in $w$ from reported level to level. These reference (ref) values emerged from multiple rounds of test analyses and inspections of analyzed skew $T-\log p$ diagrams versus spreadsheets of the input data. The following abbreviations and final values of our reference values reflect our preference for greater accuracy over sensitivity in the WML detection in North Africa:

- Top of the analysis column is $500 \mathrm{hPa}\left(p_{\text {ref }}\right)$.

- Bottom of the analysis column ( $\left.z_{\text {bref }}\right)$ depends on location.

- Maximum value of $w\left(w_{\text {ref }}\right)$ is $0.007 \mathrm{~kg} \mathrm{~kg}^{-1}$.

- Maximum change in $\theta$ with height $(\partial \theta / \partial z)_{\text {ref }}$ is $1.0 \mathrm{~K} \mathrm{~km}^{-1}$.

- The reference maximum change in $w$ with height $(\partial w / \partial z)_{\text {ref }}$ is $0.0008 \mathrm{~kg} \mathrm{~kg}^{-1} \mathrm{~km}^{-1}$.

- The actual maximum allowable change in $w$ between two levels $\left(l_{2}\right.$ and $\left.l_{1}\right)$ is scaled by the layer mean $w\left(\bar{w}_{l_{2}-l_{1}}\right)$ and $w_{\text {ref }}$, thus $\left(\bar{w}_{l_{2}-l_{1}} / w_{\text {ref }}\right)(\partial w / \partial z)_{\text {ref }}$.

The choice to use a reference height above ground level $z_{\text {bref }}$ rather than a pressure level acknowledges that analysis points in any land-based dataset may occur at elevations ranging from near sea level (e.g., Dakar, Douala) to well above $1000 \mathrm{~m}$ (e.g., Tamanrasset, Asmara). In desert ecoregion provinces, the surface layer is often superadiabatic due to the intense surface sensible heat flux (Bounoua and Krishnamurti 1991; Warner 2004). Such a lapse rate is relatively easy to identify and to program an exclusion. For our barren, hyperarid Saharan-classified stations, the value of $z_{\text {bref }}$ is 0 . However, at our "non-Saharan" and for selected months at our "mixed" stations, there may be significant mechanical mixing due to surface roughness and/or lowlevel monsoon or sea breeze inflows (Parker et al. 2005; Gounou et al. 2012). At these stations, the value of $z_{\text {bref }}$ is $500 \mathrm{~m}$. It was easier to exclude the lowest part of the boundary layer (accuracy over sensitivity) than to attempt to separate buoyant from mechanical mixing at analysis points in different environments.

Appropriate literature and the realities of data density in the IGRA raobs guided the choice of the top of the analysis column $\left(p_{\text {ref }}\right)$. For this reference value, it was easier and more uniform across different types of data inputs to use a pressure level. Above $500 \mathrm{hPa}$, even for raobs containing both mandatory and significant levels, the vertical resolution of observations and the availability of valid dewpoint depression values greatly decrease. In studies using research flight data over the western Sahara, Saharan mixed and residual layers do not extend above $6 \mathrm{~km} / 450 \mathrm{hPa}$ (Messager et al. 2010; Marsham et al. 2013). If only the mandatory radiosounding levels are reported below $500 \mathrm{hPa}$, a raob's 

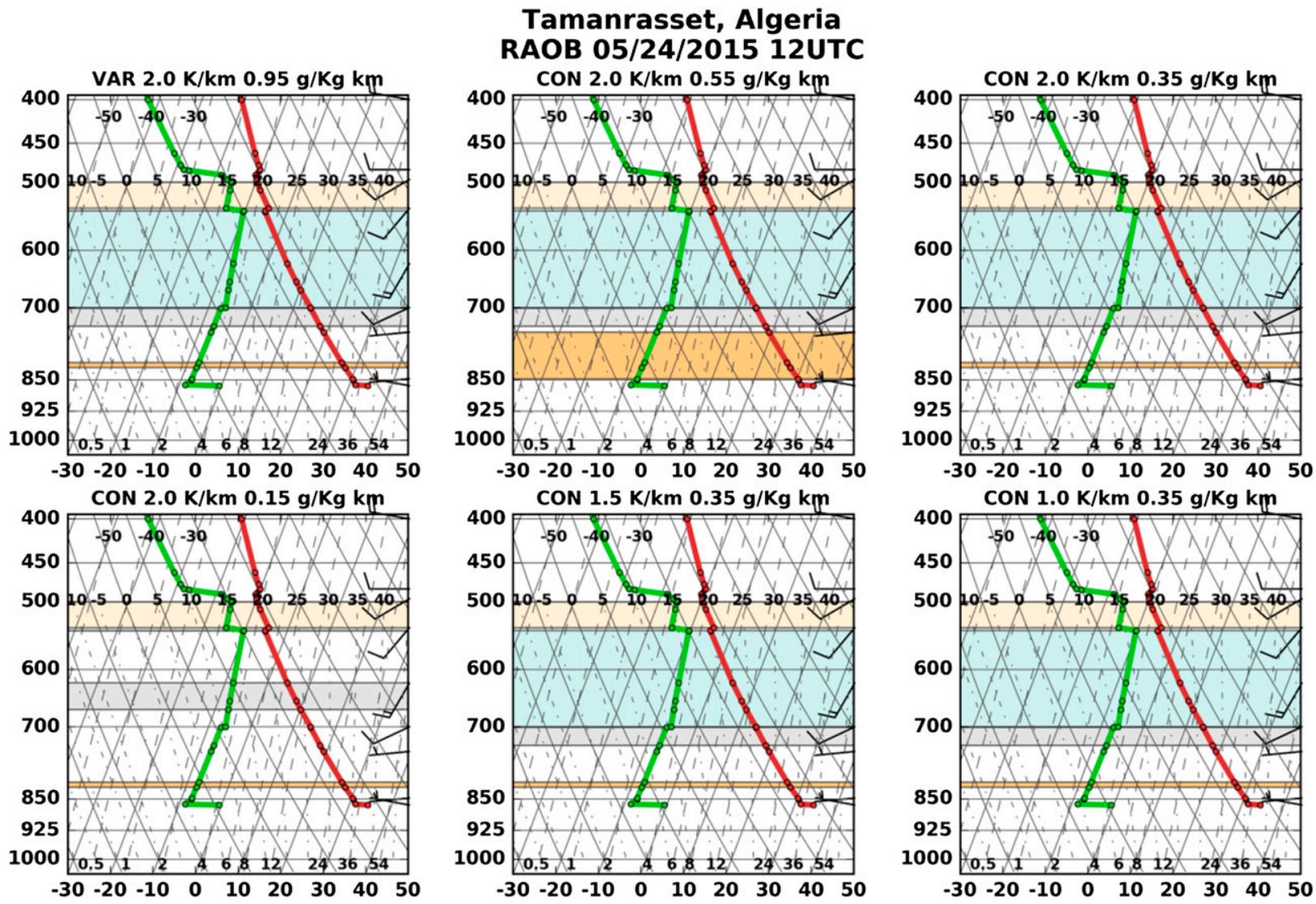

FIG. 3. Algorithm-analyzed WML detections (shaded) from a Tamanrasset raob observation using several maximum allowable potential temperature and mixing ratio lapse rates parameterizations. Water vapor mixing ratio lapse rates either scale with the layer mean mixing ratio (VAR) or are constant (CON). For each panel, the potential temperature lapse rate is fixed at the rate shown. The first analyzed WML is shaded orange, the second gray, the third cyan, and the fourth manila. Shown wind barbs are in $\mathrm{m} \mathrm{s}^{-1}$. Additional lapse rate parameterization options for this case are shown in the supplemental material as Fig. S1.

data density is considered low. However, the vertical resolution of model and remote sensing products may not be much better than raobs with just mandatory levels. To maximize our ability to use the IGRA raobs and multiple other inputs, we decided to include raobs containing just mandatory levels in our algorithm development and to analyze only to a pressure level of $500 \mathrm{hPa}$.

We derived the maximum mixing ratio $w_{\text {ref }}$, our "dry" value, from a cumulative frequency distribution analysis of $w$ from a calendar year's set of raobs at In Salah, Casablanca, and Agadez. Choosing 2007 at random to analyze, we found that $0.007 \mathrm{~kg} \mathrm{~kg}^{-1}$ is the 90 th percentile value for $w$ at In Salah, occurring exclusively in the lowest $50 \mathrm{hPa}$ of the atmospheric column. The 90th percentile value at In Salah is also the 90th percentile at Casablanca above the summertime subsidence inversion capping the marine layer and above the monsoon layer at Agadez, indicated by low-level southwesterlies. During testing using other years and stations, we did not find it necessary to adjust the value of $w_{\text {ref }}$ from our first guess.

The first guess values for the changes in $w$ and $\theta$ with height had to be within the sensitivity of radiosounding sensors and ground tracking stations (Office of the Federal Coordinator of Meteorology 1997) and potentially achievable by other inputs such as retrieved temperature and humidity from space-based sounders (Menzel et al. 2018). Our first guess for isentropic conditions, $(\partial \theta / \partial z)_{\text {ref }}$, was $1.0 \mathrm{~K} \mathrm{~km}^{-1}$, derived from Bounoua and Krishnamurti (1991) who determined that $3 \mathrm{~K} 3000 \mathrm{~m}^{-1}$ was a representative lapse rate over an entire Saharan mixed layer. This first guess proved to be a widely useful reference value. For nearly constant $w,(\partial w / \partial z)_{\text {ref }}$, we started with a value estimated from hand analysis of several midsummer raobs from In Salah, $0.002 \mathrm{~kg} \mathrm{~kg}^{-1} \mathrm{~km}^{-1}$.

Starting from these initial lapse rate values, we evaluated the sensitivity of analyzed WML detections to the allowable mixing ratio and potential temperature lapse 

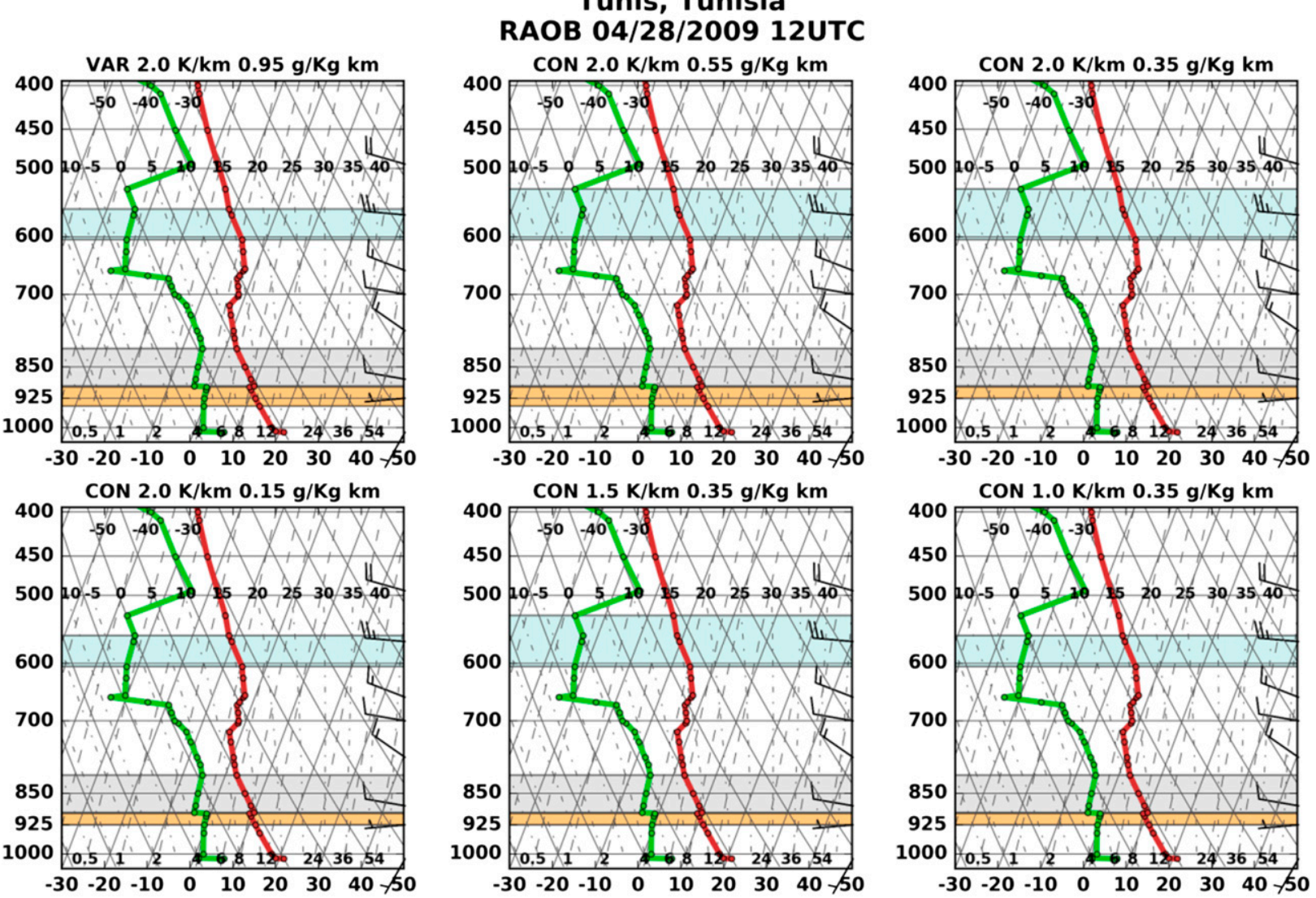

FIG. 4. As in Fig. 3, but for Tunis. Additional lapse rate parameterization options for this case are shown in the supplemental material as Fig. S2.

rates for a selection of North African raob launch locations (Fig. 1). Figures 3 and 4 show analyzed WMLs (each WML is a different color) from two representative raob profiles from Tamanrasset, Algeria, and Tunis, Tunisia, respectively. These figures show a subset of six tested configurations where $(\partial \theta / \partial z)_{\text {ref }}$ was constant and $(\partial w / \partial z)_{\text {ref }}$ was either constant $(\mathrm{CON})$ or was scaled by $\left(\bar{w}_{l_{2}-l_{1}} / w_{\text {ref }}\right)$ (VAR). Figure 3 shows the algorithm to have greater sensitivity to changes in the maximum allowable mixing ratio lapse rate than the maximum allowable potential temperature lapse rate. Qualitative analysis of this and other raob profiles (see Fig. 4 and online supplemental figures) show our initial guess for $(\partial \theta / \partial z)_{\text {ref }}$ works well, yet smaller values of $(\partial w / \partial z)_{\text {ref }}$ were needed to improve consistency with hand analysis. We found the best results for North Africa applied a maximum allowable potential temperature lapse value of $1.0 \mathrm{~K} \mathrm{~km}^{-1}$ and a maximum allowable mixing ratio lapse rate value of $0.00035 \mathrm{~kg} \mathrm{~kg}^{-1} \mathrm{~km}^{-1}$ (constant)/ $0.0008 \mathrm{~kg} \mathrm{~kg}^{-1} \mathrm{~km}^{-1}$ (scaled). Smaller and larger lapse rate values produced less accurate WML detections because the detection criteria were either too constraining or generous, respectively. Figure 4 reveals that applying a constant allowable mixing ratio lapse for WML analysis in North Africa has an inherent flaw. Specifically, if the mixing ratio profile approaches or falls below the allowed mixing ratio change over $1 \mathrm{~km}$ then any isentropic layer is identified as WML regardless of the dewpoint temperature profile (see Fig. 4, $\sim 550 \mathrm{hPa}$ ). As shown in Fig. 4, this flaw can be addressed by scaling the maximum allowable mixing ratio lapse rate by $\left(\bar{w}_{l_{2}-l_{1}} / w_{\text {ref }}\right)$. This adjustment is included in our study because it ensures that all analyzed WMLs contain dewpoint temperature profiles that are always roughly parallel to lines of constant mixing ratio. Properly tuning the allowed mixing ratio lapse rate is crucial for WML detection because isentropic layers in North Africa are generated by dry convection (our interest), large-scale subsidence, and shear-based turbulence (Moeng and Sullivan 1994; Conzemius and Fedorovich 2006).

In the development phase, we encountered inputs with marginally acceptable data densities below $500 \mathrm{hPa}$, such as soundings with only mandatory levels 


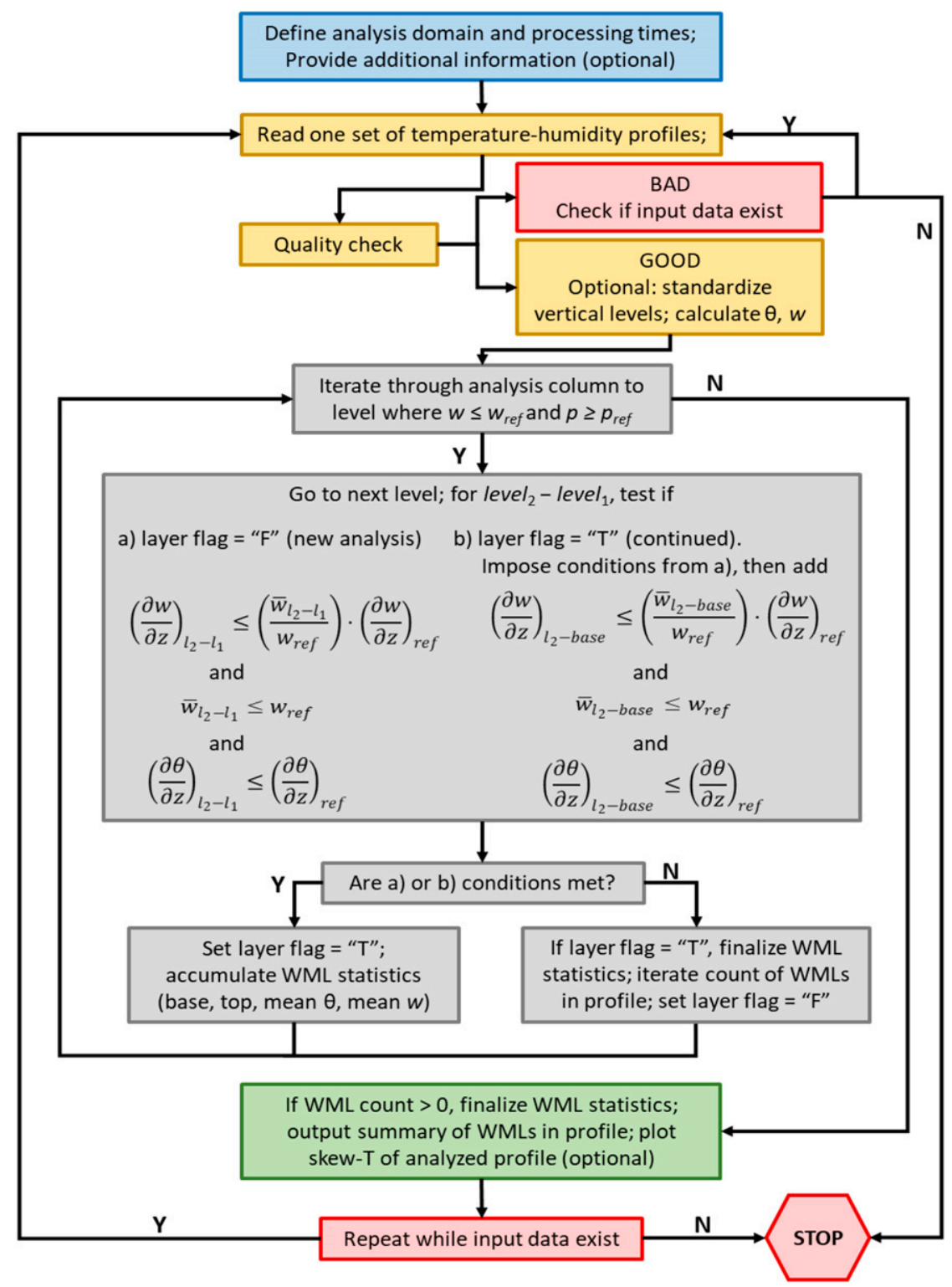

FIG. 5. Decision tree of the WML detection software. The blue box is the analysis setup. The yellow boxes indicate data input. Gray boxes contain the analysis decisions. The green box contains output actions. Red boxes at the top and bottom control program execution.

and at high-altitude synoptic stations, such as Asmara $(2325 \mathrm{~m})$. We also had plenty of examples where the analyzed and plotted WMLs looked smaller than those that might be hand analyzed on a skew $T-\log p$ chart. For inputs of poor data densities or if the user requires a more generous interpretation of "well mixed," less restrictive values can be set, for example, $(\partial \theta / \partial z)_{\text {ref }}$ at $2.0 \mathrm{~K} \mathrm{~km}^{-1},(\partial w / \partial z)_{\text {ref }}$ at $0.00095 \mathrm{~kg} \mathrm{~kg}^{-1} \mathrm{~km}^{-1}$ (scaled allowable mixing ratio lapse rate), or $(\partial w / \partial z)_{\text {ref }}$ at $0.00035 \mathrm{~kg} \mathrm{~kg}^{-1} \mathrm{~km}^{-1}$ (constant allowable mixing ratio lapse rate). The adjustability of the software makes it possible to adapt the detection methodology for user preferences, other types of WMLs (e.g., moist wellmixed layers), and other regions.

\section{b. The WML analysis process}

Figure 5 is the decision tree of the software. During the initial development of the decision tree, we used about $10 \%$ of the IGRA database, selecting a sample of soundings scattered across seasons, years, and stations (Fig. 1). The software is written in multiple Python modules that govern the basic information flow, setup (blue) to input data (yellow) to data evaluation (gray) to output (green). The execution (red) is controlled at both 
the top and the bottom of the tree, depending on both data input availability and quality. The setup module (blue box) governs the setting of analysis period and location. "Additional information" can be interpreted as broadly as the user needs, to include anything needed for analysis that is not already in the input files. For example, if an analysis location is not contained within the NCEI IGRA station inventory, then the location name and position will have to be added manually. The setup module is also the entry point where the user can group analysis points as we did into categories for different treatment of the base of the analysis column $z_{\text {bref }}$. While we created individual submodules within the input module to read each type of data used in this study, the yellow boxes in Fig. 5 represent the generalized reading and quality checking of any type of input data. If the user's work plan involves input from multiple data sources, the user can either preserve the native vertical resolution of each useful profile or linearly interpolate all useful profiles to the pressure levels associated with the least vertically dense input data. Since some dataset providers may already have $\theta$ and $w$ available for download, calculating these variables may or may not be necessary.

The detection (gray boxes) begins with the search for the first level in the analysis column, that is, between $z_{\text {bref }}$ and $p_{\text {ref }}$, where $w$ is at or less than $w_{\text {ref }}$. This level becomes level ${ }_{1}$. Starting with a new analysis (column a), the next higher level in the profile is designated level ${ }_{2}$, and the changes in $\theta$ and $w$ are assessed $\left(l_{2}-l_{1}\right)$, providing the layer mean $w$ is at or below $w_{\text {ref. }}$. If all of these conditions are met $(\mathrm{Y})$, a detection flag is set indicating that a WML exists [true (T)], and a set of statistics on the WML starts to accumulate. Both the positive outcome and the negative outcome $(\mathrm{N})$ below the analysis box return to the upward iteration of vertical levels in the analysis column. If the new level's $w$ is at or below $w_{\text {ref }}$ and the WML flag is true, a multilevel WML exists, and column $\mathrm{b}$ is invoked. For a multilevel WML, not only must the current layer $\left(l_{2}-l_{1}\right)$ meet the $\theta$ and $w$ change and mean $w$ conditions, but the entire presumptive WML from the previously identified base to level ${ }_{2}$, ( $l_{2}$-base), must meet those same conditions. Notably, the algorithm permits the user to apply either a scaled or constant maximum allowable mixing ratio lapse rate [i.e., $\left(\bar{w}_{l_{2}-l_{1}} / w_{\text {ref }}\right)=1$ ]. The cycle of iteration up the analysis column and the testing of change conditions continue until the change conditions are no longer satisfied, or the top of the analysis column is reached.

If the change conditions fail, a counter iterates to record that a WML has been detected in the analysis column, and the statistics for that WML stop accumulating. We now know its location and thickness in the analysis column and its mean $\theta$ and $w$. Resetting the flag to false $(F)$ starts the search for another suitable layer for analysis. If the top of the analysis column $p_{\text {ref }}$ is reached, the count of WMLs and a summary of the WML characteristics for that profile set are finalized in the output module (green box). The output module also has an option to plot an analyzed skew $T-\log p$ with different colors indicating each of the WMLs detected in the profile. The user can generate skew $T-\log p$ plots at any resolution or file format supported by Python including postscript (.ps), encapsulated postscript (.eps), and portable network graphics (.png) images. Reading and quality checking input data continue until end-of-file conditions (red boxes) occur.

\section{Detection examples}

\section{a. Raob examples}

Figure 6 contains archetypal examples of analyzed IGRA raobs with WMLs. The WMLs (orange shaded areas) in Fig. 6 can originate from local dry convective mixing during the current day, residual boundary layers from previous days, or transport from an upstream desert where the dry convection occurred (e.g., Bounoua and Krishnamurti 1991; Messager et al. 2010; Garcia-Carreras et al. 2015). In addition, soundings may contain radiation and subsidence inversions with or without WMLs. In Fig. 6a, In Salah has a superadiabatic surface layer below $972 \mathrm{hPa}$ due to intense surface heating and a single, deep WML characteristic of inner Saharan locations during the summer months. In Fig. 6b, the coastal city of Tunis has a marine boundary layer capped by a deep subsidence inversion and a WML from 648 to $533 \mathrm{hPa}$. Figures $6 \mathrm{c}$ and $6 \mathrm{~d}$ are from the mixed category station, Agadez, on the southern edge of the Sahara, demonstrating profiles before and after the onset of the West African monsoon. Figure $6 c$ contains a typical late spring-early summer profile before monsoon onset. There is a surface layer below $949 \mathrm{hPa}$ and a WML from 925 to $700 \mathrm{hPa}$, similar to In Salah (Fig. 6a), but shallower. Figure 6d is an example of Agadez during the West African monsoon season, containing a monsoon layer below $850 \mathrm{hPa}$, a WML from 817 to $700 \mathrm{hPa}$, and a subsidence inversion starting at $541 \mathrm{hPa}$.

Figure 7 has examples of more challenging environments to analyze. In early May, the surface heating at In Salah (Fig. 7a) is not as intense as in midsummer (Fig. 6a). In Fig. 7a, there are two analyzed WMLs from 925 to $500 \mathrm{hPa}$. There is a larger than allowable change in $w$ from 976 to $925 \mathrm{hPa}$, so that the first WML 

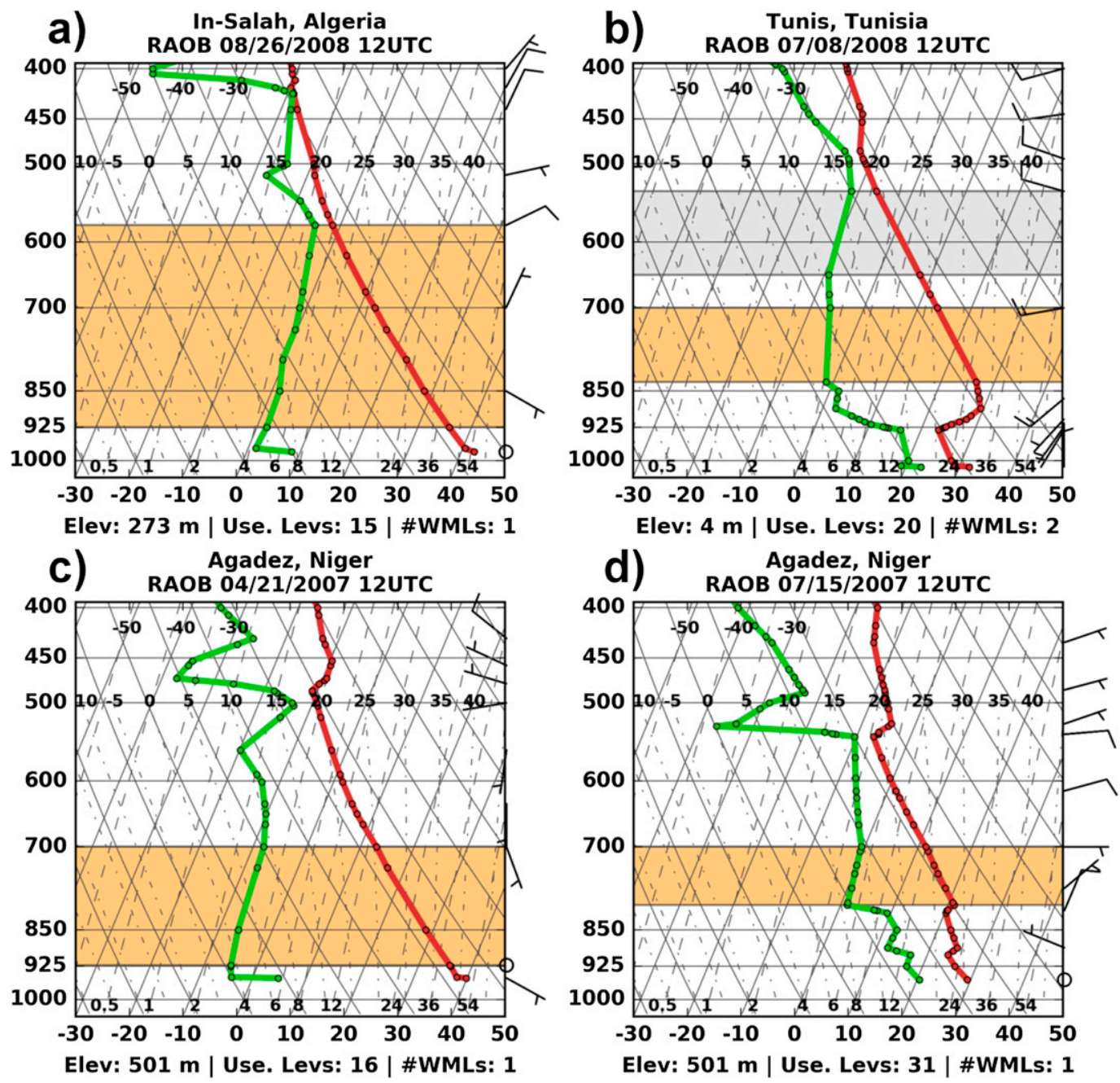

FIG. 6. Archetypal raobs of vertical structures found in North Africa. The red and green lines represent the temperature and dewpoint vertical profiles, respectively, and the orange shaded layer denotes algorithm-detected WMLs. The station elevation (m), number of useful levels in the analysis column, and the number of detected WMLs are indicated. (a) The profile at In Salah is typical of summertime low-elevation inner Saharan stations. (b) The profile at Tunis is typical of northern coastal stations. (c) Agadez is on the southern edge of the Sahara, but the West African monsoon reaches Agadez during July and August. This is a typical late spring-early summer profile at Agadez before monsoon onset. (d) An example at Agadez during the monsoon season.

(orange) starts at $925 \mathrm{hPa}$. It terminates at $850 \mathrm{hPa}$ because of the larger than allowable changes in $\theta$ between 850 and $792 \mathrm{hPa}$. The second WML (gray) extends from $792 \mathrm{hPa}$ to the top of the analysis column at $500 \mathrm{hPa}$. The probability that the mixing in today's boundary layer will erode through the previous night's residual layer, as in Figs. 6a and 6c, depends upon the intensity of the surface heating (Messager et al. 2010; Garcia-Carreras et al. 2015). Growth of the current day's mixed layer can be limited by reductions in surface heating such as suppressed insolation due to dust (Marsham et al. 2008; Marsham et al. 2016), or to airmass changes, or to cloudiness from topographically induced circulations, transient extratropical waves, or organized convection associated with tropical waves (Knippertz et al. 2009; Vizy and Cook 2009; Knippertz and Todd 2010; Birch et al. 2012; Bou Karam et al. 2014). If the boundary layer growth is insufficient to mix out the remnant residual layers, then multiple WML layers can occur as in Fig. 7a. The slight cooling that takes place as the afternoon mixed-layer transitions to the nighttime residual layer marks it as a different WML than the next day's mixed layer (Cuesta et al. 2008; Cuesta et al. 2009; Messager et al. 2010). The ability to analyze, quantitatively and uniformly, multiple soundings from the previous days allows cross 

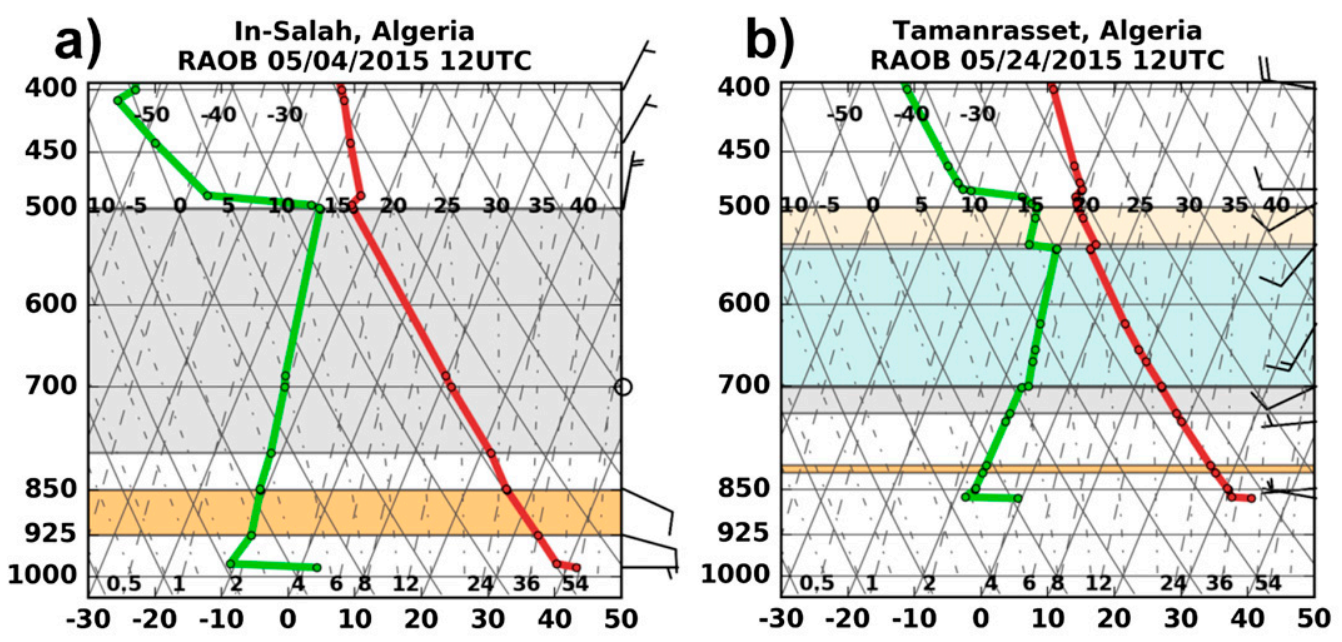

Elev: 273 m | Use. Levs: 10 | \#WMLs: 2
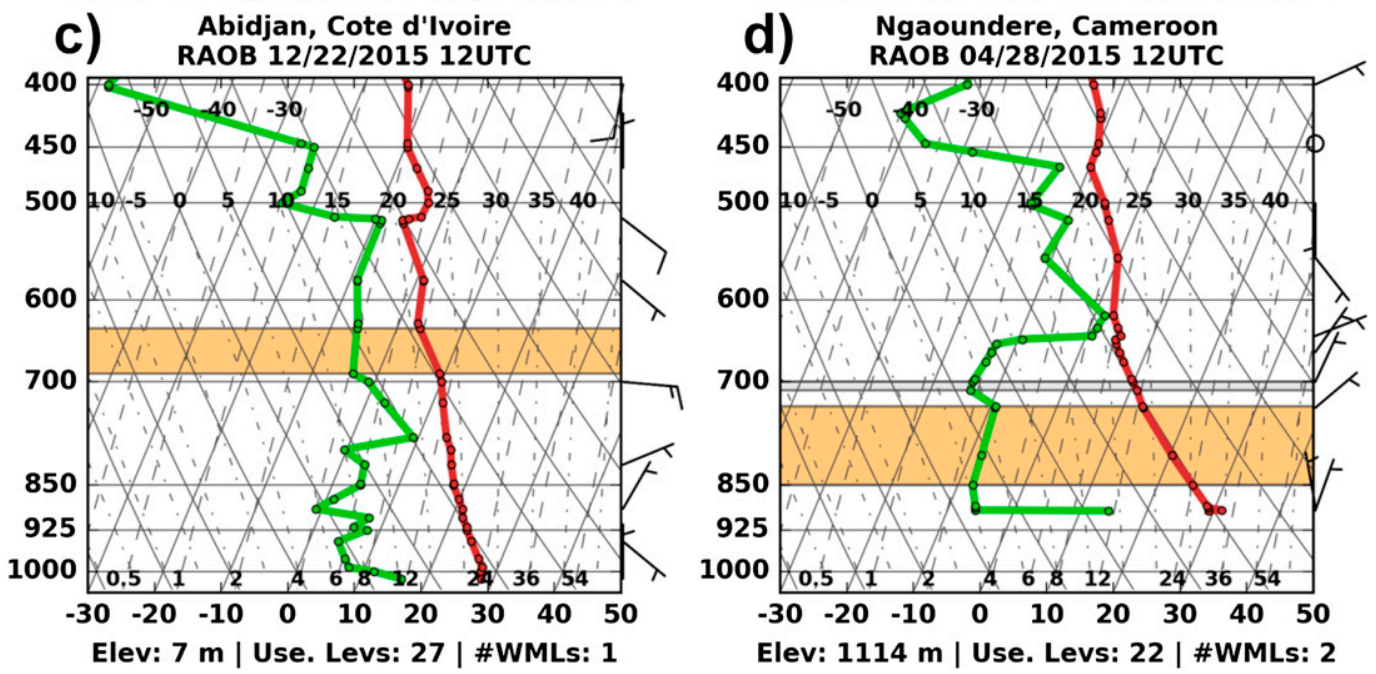

FIG. 7. Examples of more challenging daytime environments from 2015 at (a) In Salah and (b) Tamanrasset in the spring; (c) Abidjan in the winter; (d) Ngaoundéré in the spring prior to the monsoon onset. The first analyzed WML is shaded orange, the second gray, and the third cyan.

checking and confirmation of layered midtropospheric structure due to local diurnal boundary layer processes.

Tamanrasset (Fig. 7b) is an oasis city in the Hoggar Mountains with less intense surface heating and dry convection than In Salah (Cuesta et al. 2008; Wahab et al. 2010), yet it presents a complex profile with four analyzed WMLs. The two analyzed WMLs (orange and gray shading) between the surface layer and $700 \mathrm{hPa}$ ( 834 to 825 and 734 to $700 \mathrm{hPa}$ ) demonstrate the capability of the decision tree to detect subtle variability in the profile mixing ratio lapse rate with height, which is not be easily attained from hand analysis. This is best illustrated in Fig. 3 (same case as Fig. 7b), where altering the maximum allowable mixing ratio lapse rate by just $0.0002 \mathrm{~kg} \mathrm{~kg}^{-1} \mathrm{~km}^{-1}$ yields a vastly different
WML analysis. Above $700 \mathrm{hPa}$, the blue shading indicates the third WML (700-541 hPa) and a fourth old residual layer (manila) between 536 and $500 \mathrm{hPa}$. The lower panels of Fig. 7 are from locations outside of the Sahara, Abidjan (Fig. 7c) and Ngaoundéré (Fig. 7d). Abidjan is in the Bailey's ecoregion province "humid forests with short dry season" (Fig. 1), and the raob is from that short winter dry season. There is a WML from 689 to $627 \mathrm{hPa}$ but not one above $600 \mathrm{hPa}$, as the change in $\theta$ is too large. At Ngaoundéré's premonsoon onset raob, there one shallow WML analyzed between 850 and $735 \mathrm{hPa}$ and a second, smaller layer extends from 711 to $700 \mathrm{hPa}$. Another nearly isentropic layer exists from 696 to $650 \mathrm{hPa}$, but it is not identified as a WML because the change in $w$ exceeds the allowed limit. In both locations, shallow WMLs are identified despite both 
being seasonally humid locations. In future papers, we provide results from trajectory analysis that define whether these WMLs are from local boundary layer processes or transported from the Sahara.

\section{b. Examples from other datasets}

The development of the WML decision tree (Fig. 5) required a robust sample of raob observations throughout North Africa that did not need to have either temporal or spatial continuity. However, atmospheric process studies may require temporal and/or spatial continuity in temperature and humidity fields. The temporally and spatially sparse record of upper-air observations over much of the world motivated the adaptation of the detection methodology and software to ingest remote sensing and model products. In this section, we show examples of WML analysis using AIRS + AMSU and model reanalysis (ERA-I and MERRA-2) at their native vertical resolution to demonstrate the utility and sensitivity of the detection analysis with multiple different inputs. Analysis using AIRS only and the Japanese 55-year Reanalysis (JRA-55) product inputs are also possible, but are not shown for sake of brevity. As in Nicholls and Mohr (2010), we assume raob and satellite observations to be valid if they are within $3 \mathrm{~h}$ of the analysis time, whereas model reanalysis data are linearly interpolated to the analysis time. The principal intent of this section is to demonstrate and discuss how our detection algorithm analyzes WMLs across multiple data input sources under similar conditions. A more rigorous quantitative validation of the WML detection and its use in process studies of Saharan air intrusions will be treated in future papers.

Figures 8-11 are from different environments in North Africa and have four panels, with raob data in panel a, AIRS + AMSU products in panel b, ERA-I in panel $\mathrm{c}$, and MERRA-2 in panel d. Figure 8 is a summer sounding from In Salah with a shallow WML from the top of the surface layer to $925 \mathrm{hPa}$ and another, deeper WML extending from 850 to $600 \mathrm{hPa}$ (Fig. 8a). The soundings in panels $b-d$ are largely similar to the raob in panel a, with WML detections occurring near the surface and into the midtroposphere. The AIRS + AMSU profile (Fig. 8b) fails to capture the shallow WML near the surface, but it is able to largely capture the height and thickness of the WML analyzed above $850 \mathrm{hPa}$ in the raob profile. However, the mixing ratio lapse rate in the AIRS + AMSU profile does slightly exceed the allowed rate between 753 and $729 \mathrm{hPa}$, resulting in two analyzed WMLs rather than a single continuous layer. Corresponding ERA-I and MERRA-2 profiles (Figs. $8 \mathrm{c}$ and $8 \mathrm{~d}$ ) both show one deep, continuous WML extending from 950 to $650 \mathrm{hPa}$.
Unlike the raob, both reanalysis products in Fig. 8 are unable to represent the nearly isentropic, but not wellmixed layer that exists between 925 and $850 \mathrm{hPa}$. Raob winds from surface to $850 \mathrm{hPa}$ had strength (up to $10 \mathrm{~m} \mathrm{~s}^{-1}$ ) and shear (veering southeast to south), whereas in both reanalysis profiles the velocities were generally no more than $5 \mathrm{~m} \mathrm{~s}^{-1}$ and unidirectional. The presence of wind shear between 925 and $850 \mathrm{hPa}$ suggests the potential of WML erosion by mechanical turbulence from low-level winds increasing in velocity and/ or shear throughout the day (Flamant et al. 2007; Cuesta et al. 2009; Birch et al. 2012). Global models may not be able to account for turbulent local wind patterns resulting from differential heating or surface/terrain effects due to their application of relatively coarse horizontal model grids (Garcia-Carreras et al. 2013; Roberts et al. 2015). The operational AIRS + AMSU retrieval is independent of any model wind patterns and was sensitive enough to account for the decrease in $w$ with height to $850 \mathrm{hPa}$ (Susskind et al. 2014; Milstein and Blackwell 2016). The model data assimilation schemes may not have been sensitive enough to retrieve realistic profiles of $w$ below $850 \mathrm{hPa}$ from AIRS + AMSU radiances nor allow this information to override information from other model fields (Faccani et al. 2009; AgustíPanareda et al. 2010; Fink et al. 2011). Unlike both reanalysis models and the AIRS + AMSU retrieval, the raob shows an abrupt transition from WML to a subsidence layer at $600 \mathrm{hPa}$. Comparatively, the reanalysis models and the AIRS + AMSU retrieval have smoother, deeper transitions, as their vertical resolutions are becoming much larger at this point in the troposphere.

Dakar, on the west coast of West Africa, has a marine layer in the lowest portion of its raob in Fig. 9 and a single analyzed WML between 850 and $800 \mathrm{hPa}$. Model soundings (Figs. 9c and 9d) successfully replicate the presence of marine layer above Dakar due to their assimilation of raob data. Differences in horizontal grid spacing yield interpolated profiles that produce analyzed WMLs at notably different pressure levels (ERA-I: 650-700 hPa; MERRA-2: 850-825 hPa). The AIRS + AMSU profile (Fig. 9b) is clearly hindered by its low sensitivity to abrupt atmospheric property changes in the vertical, yet is improved by its higher horizontal data resolution $(13.5 \mathrm{~km}$ at nadir) as compared to model reanalysis products $(+60 \mathrm{~km})$. The resulting profile lacks a defined marine layer, but the AIRS + AMSU analyzed WML is largely consistent with raob data.

Similarly, the models have a more detailed, although not faultless, representation of the column above Ouagadougou in Fig. 10. On this June date in the raob 

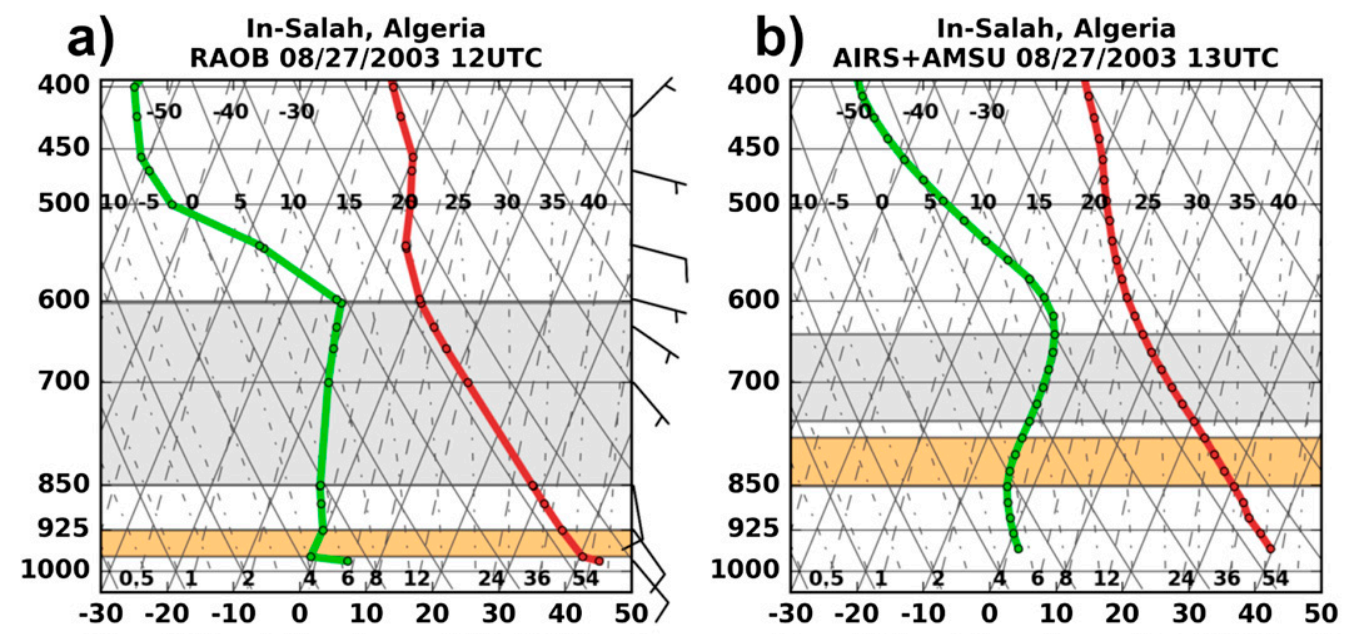

Elev: 273 m | Use. Levs: 14 | \#WMLs: 2

Elev: 522 m | Use. Levs: 20 | \#WMLs: 2
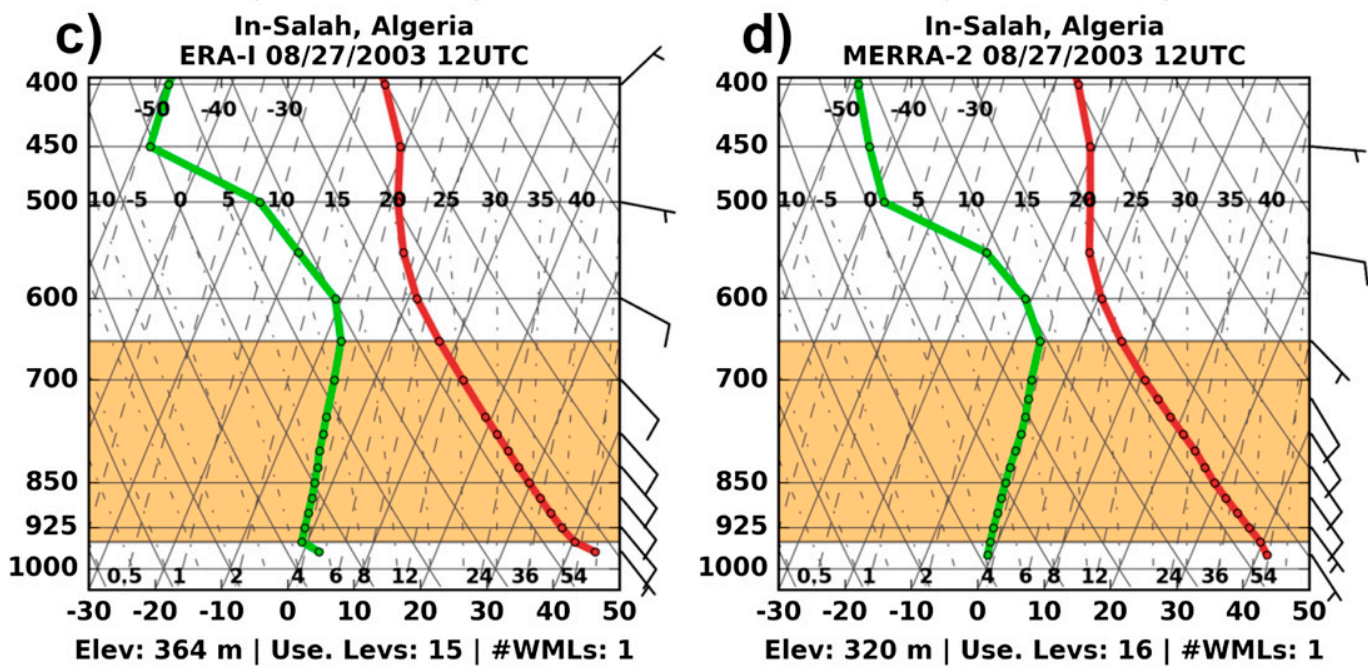

FIG. 8. Four-panel figure comparing WML detections at In Salah in the summer from (a) raob data, (b) AIRS + AMSU temperature and humidity products, (c) ERA-I reanalysis, and (d) MERRA-2 reanalysis. The orange shading in each panel is the first WML detected in that profile.

(Fig. 10a), the West African monsoon is apparent below $925 \mathrm{hPa}$, and there is a WML from 700 to $600 \mathrm{hPa}$. Both reanalysis products also have narrower WMLs analyzed in the same general region above a deep, dry subsidence layer, but the AIRS + AMSU profile lacks any analyzed WMLs between 600 and $700 \mathrm{hPa}$ because missing ratio lapse rate slightly exceeds the maximum allowed value. In the example at Tunis (Fig. 11), the vertical structure of its column is less complex than the example at Ouagadougou. The ERA-I (Fig. 11c) best approximates the raob profile, yet no data product (retrieval or model) show more than a hint of the marine layer present in the raob profile. The raob has a WML analyzed from 724 to $593 \mathrm{hPa}$ between subsidence layers. Both model products have WMLs analyzed around $700 \mathrm{hPa}$, with MERRA-2 exhibiting a smaller WML between 850 and $825 \mathrm{hPa}$, which is not present in the raob profile. The AIRS + AMSU and MERRA-2 profiles are largely similar to each other, but the steep mixing ratio lapse rates associated the AIRS + AMSU profile prevent any WML detections whatsoever. It cannot be determined just from the profiles in Fig. 11 why the MERRA-2 is less successful than ERA-I in capturing the general structure reflected in the raob, particularly the depth of the subsidence between the marine layer and $700 \mathrm{hPa}$. Information from other model fields (not explored here) may have contravened the information from the assimilation of both raob data and AIRS + AMSU radiances.

For the sake of brevity, additional examples will not be shown and additional analysis left to future papers. The multiple examples from around North Africa 

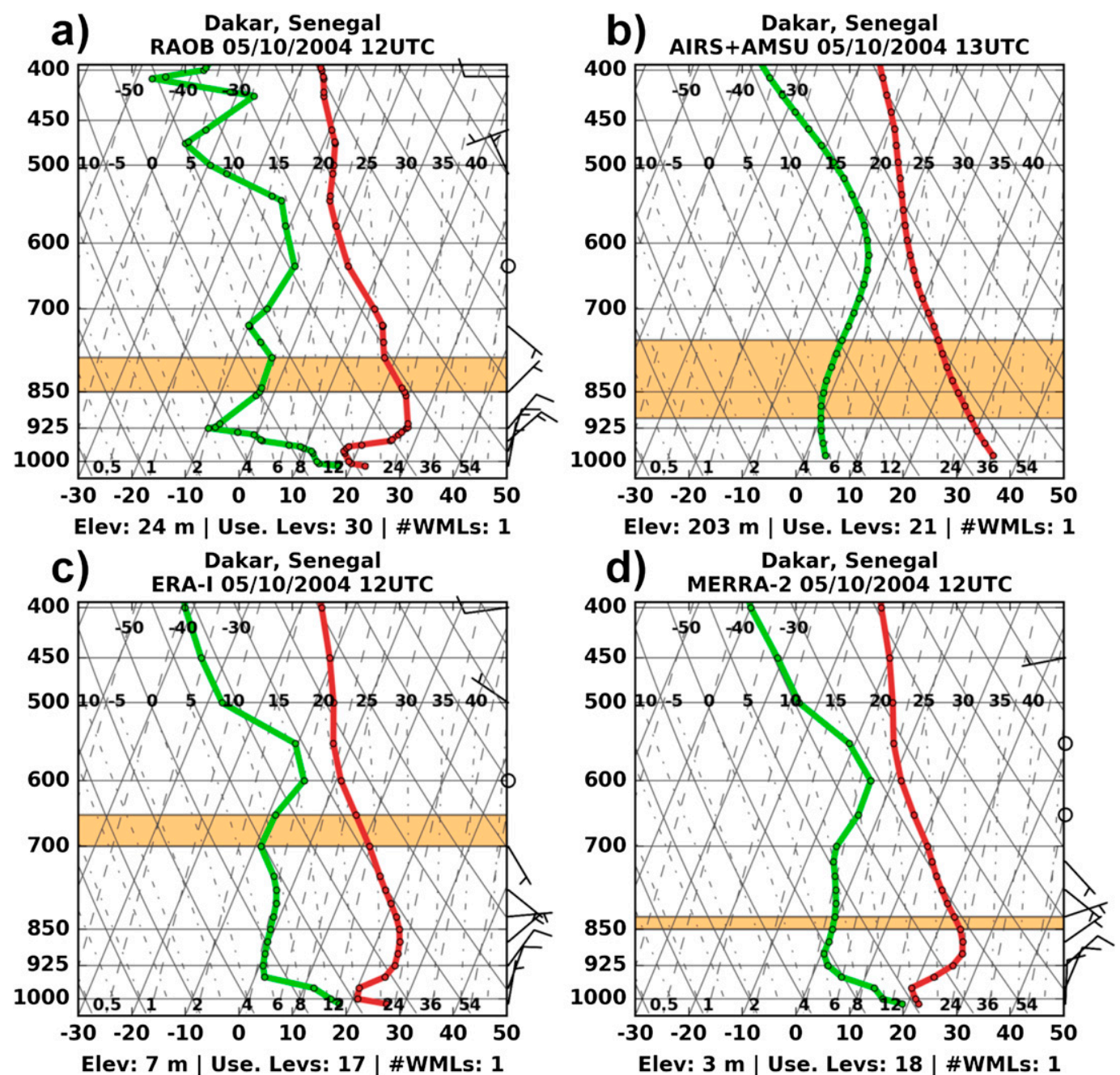

FIG. 9. As in Fig. 8, but for springtime in Dakar.

in this paper reveal how complex vertical structures due to multiple processes from local-scale surface heating gradients to continental-scale subsidence can occur in any season. The WML detection methodology can identify these layers anywhere within the analysis column, even between subsidence layers (e.g., Fig. 11a), or if there are multiple WMLs (e.g., Fig. 7) due to memory from local boundary layer processes from previous days.

\section{Conclusions}

Intense surface heating over dry land surfaces can produce strong dry convection. The resulting WMLs are characterized by nearly constant potential temperature and low, nearly constant water vapor mixing ratio. The WML is a frequent feature of dryland boundary layer processes. Transported downstream over low-level moist airstreams, WMLs can affect the potential for intense deep convective clouds. To further the study of WMLs, we created a detection methodology and supporting software to automate the identification and characterization of WMLs from multiple data sources including raobs and remote sensing and model products. The software is modular code written in Python, an open-source language.

The network of synoptic stations in North Africa was a challenging and varied testing ground for methodology development, containing stations in hyperarid desert to humid tropical forest ecoregions. We used raobs from all seasons to develop and then test our parameter values and layer identification process. Parameter values that required setting included the analysis column (top of the surface layer to $500 \mathrm{hPa}$ ), our maximum water vapor mixing ratio, and maximum 

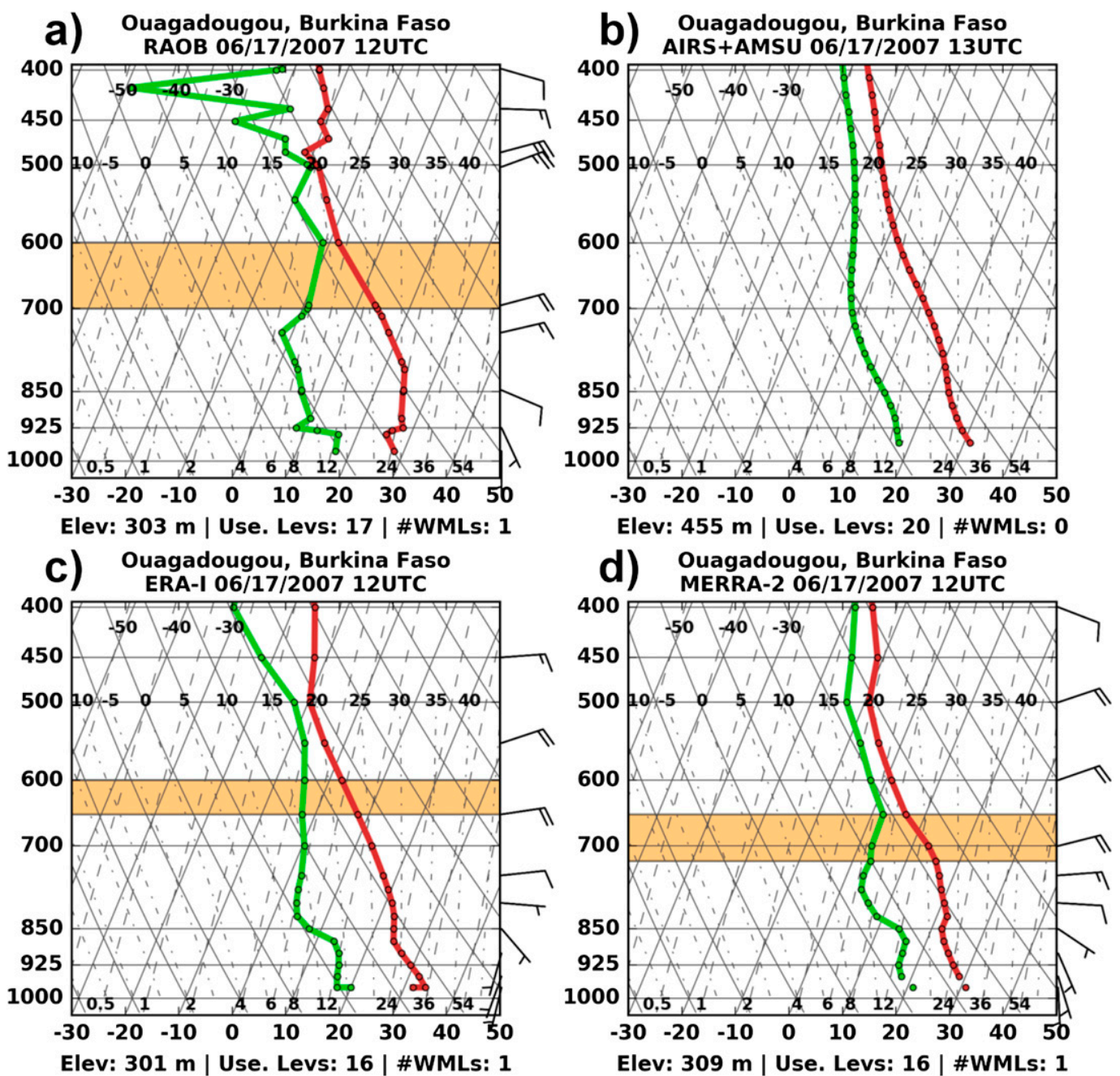

FIG. 10. As in Fig. 8, but for springtime in Ouagadougou.

allowable changes with height in water vapor mixing ratio and potential temperature. These parameters govern an iterative decision tree that ingests a sounding from an input data file, performs a quality check for sufficient data density, and then searches up through the column for successive points where the changes in water vapor mixing ratio and potential temperature are less than specified maxima. If points in the sounding meet the identification criteria, statistics are generated on layer characteristics (e.g., layer base, top, mean potential temperature), and a count of layers in the profile is started. At the top of the analysis column, any layer accounting ceases and a summary of the WMLs in the sounding is generated. There is an option to plot analyzed soundings in a variety of file formats.

Because of temporally and spatially sparse upperair data records in many parts of the world, we adapted the software package to ingest remote sensing and gridded model products such as AIRS + AMSU temperature and humidity profiles and MERRA-2 reanalysis. The software has separate submodules for different types of input, and analysis parameter values can be adjusted as appropriate to the data source or the user's preferences for detection sensitivity. The examples of different input datasets shown in this paper used the same parameter values. While the remote sensing and model product profiles did not capture all of the complexity in the vertical columns above the synoptic stations used as examples, the detection methodology was sensitive enough to identify WMLs in those products in the same area of the midtroposphere as the comparison raobs. We intend to examine more broadly and deeply the performance of remote sensing and model products versus raobs as the next step in using our detection 

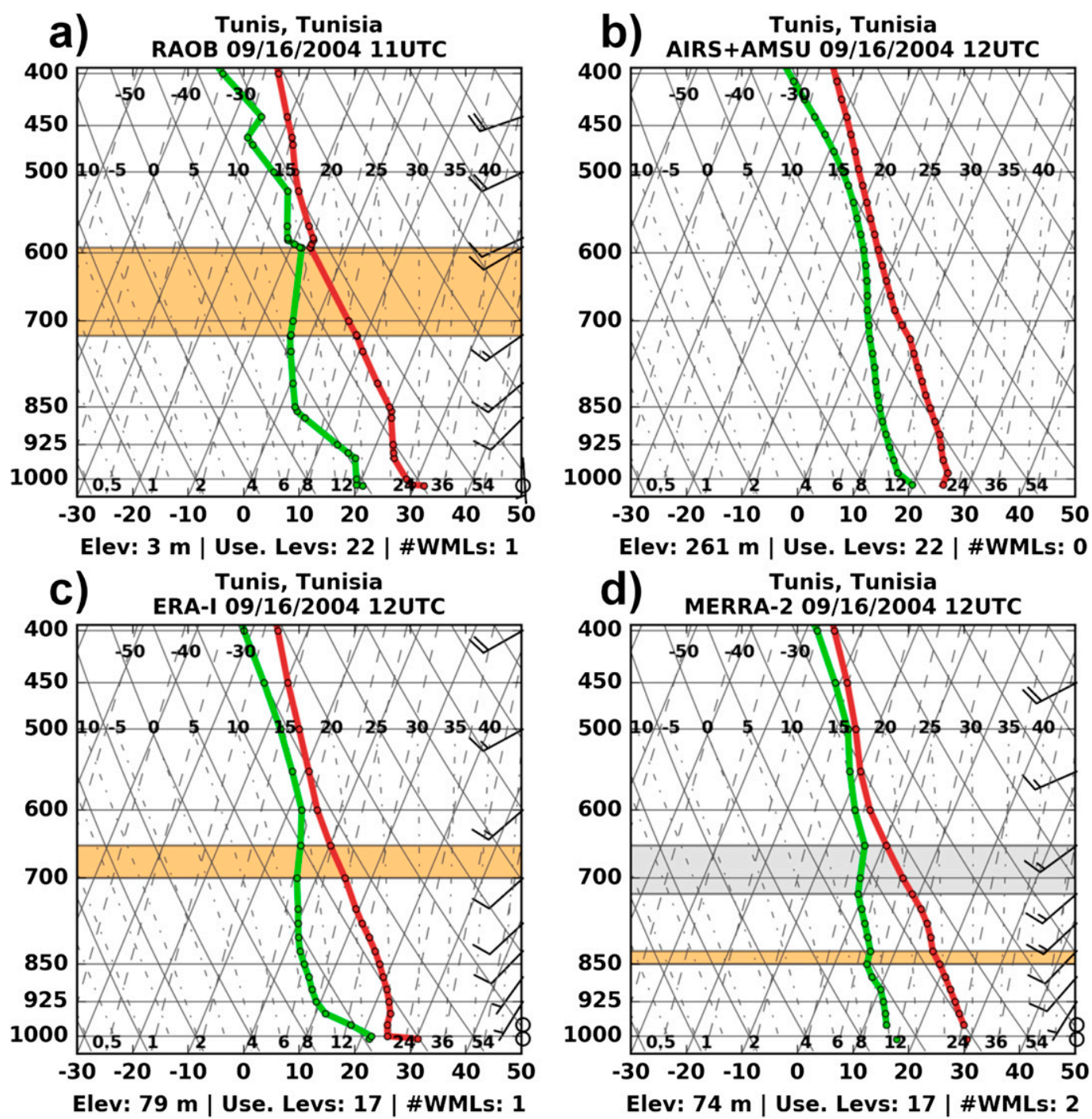

FIG. 11. As in Fig. 8, except for summertime in Tunis.

methodology in process studies of desert-sourced dry well-mixed airstreams.

Acknowledgments. This work would not have been possible without the support of the Science of Terra and Aqua program, Atmospheric Science Measurement Team (Program Scientist, R. Kakar, NASA HQ), and the support of the Modeling, Analysis, and Prediction (Program Scientist, D. Considine, NASA HQ). Data came from multiple sources: NOAA NCEI, USDA Forest Service, NCAR DSS, and NASA's GMAO and GES DISC. We had help and advice on AIRS + AMSU products from the Goddard Sounder Research Team (J. Susskind, L. Iredell, J. Blaisdell) and the DISC (T. Hearty, A. Savtchenko, C. Shie). We also had useful discussions with O. Reale, S. Braun, R. Shi, and S. Lang.
The software can be downloaded from the Goddard Cloud Library (https://portal.nccs.nasa.gov/cloudlibrary/). We thank our reviewers for greatly improving this manuscript and suggesting useful changes to the analysis process.

\section{REFERENCES}

Agustí-Panareda, A., A. Beljaars, C. Cardinali, I. Genkova, and C. Thorncroft, 2010: Impact of assimilating AMMA soundings on ECMWF analyses and forecasts. Wea. Forecasting, 25, 1142-1160, https://doi.org/10.1175/2010WAF2222370.1.

Allen, J. T., and D. J. Karoly, 2014: A climatology of Australian severe thunderstorm environments 1979-2011: Inter-annual variability and ENSO influence. Int. J. Climatol., 34, 81-97, https://doi.org/10.1002/joc.3667.

Aumann, H. H., and Coauthors, 2003: AIRS/AMSU/HSB on the Aqua mission: Design, science objectives, data products, and 
processing systems. IEEE Trans. Geosci. Remote Sens., $\mathbf{4 1}$ 253-264, https://doi.org/10.1109/TGRS.2002.808356.

Bailey, R. G., 2004: Identifying ecoregion boundaries. Environ. Manage., 34, S14-S26, https://doi.org/10.1007/s00267-003-0163-6. , 2014: Ecoregions: The Ecosystem Geography of the Oceans and Continents. 2nd ed. Springer, $180 \mathrm{pp}$.

Benjamin, S. G., and T. N. Carlson, 1986: Some effects of surface heating and topography on the regional severe storm environment. Part I: Three-dimensional simulations. Mon. Wea Rev., 114, 330-343, https://doi.org/10.1175/1520-0493(1986) $114<0330$ :SEOSHA $>2.0 . \mathrm{CO} ; 2$.

Birch, C. E., D. J. Parker, J. H. Marsham, and G. M. Devine, 2012: The effect of orography and surface albedo on stratification in the summertime Saharan boundary layer: Dynamics and implications for dust transport. J. Geophys. Res., 117, D05105, https://doi.org/10.1029/2011JD015965.

Bissolli, P., J. Grieser, N. Dotzek, and M. Welsch, 2007: Tornadoes in Germany 1950-2003 and their relation to particular weather conditions. Global Planet. Change, 57, 124-138, https://doi.org/10.1016/j.gloplacha.2006.11.007.

Blackwell, W. J., 2005: A neural-network technique for the retrieval of atmospheric temperature and moisture profiles from high spectral resolution sounding data. IEEE Trans. Geosci. Remote Sens., 43, 2535-2546, https://doi.org/10.1109/ TGRS.2005.855071.

—_, 2012: Neural network Jacobian analysis for high-resolution profiling of the atmosphere. EURASIP J. Adv. Signal Process., 2012, 71-82, https://doi.org/10.1186/1687-6180-2012-71.

_- and A. B. Milstein, 2014: A neural network retrieval technique for high-resolution profiling of cloudy atmospheres. IEEE J. Sel. Top. Appl. Earth Obs. Remote Sens., 7, 12601270, https://doi.org/10.1109/JSTARS.2014.2304701.

Born, K., A. H. Fink, and P. Knippertz, 2010: Meteorological processes influencing the weather and climate of Morocco. Impacts of Global Change on the Hydrological Cycle in West and Northwest Africa, P. Speth et al., Eds., Springer, 150-163.

Bou Karam, D., E. Williams, M. Janiga, C. Flamant, M. McGrawHerdeg, J. Cuesta, A. Auby, and C. Thorncroft, 2014: Synopticscale dust emissions over the Sahara Desert initiated by a moist convective cold pool in early August 2006. Quart. J. Roy. Meteor. Soc., 140, 2591-2607, https://doi.org/10.1002/qj.2326.

Bounoua, L., and T. N. Krishnamurti, 1991: Thermodynamic budget of the five day wave over the Saharan Desert during summer. Meteor. Atmos. Phys., 47, 1-25, https:// doi.org/10.1007/BF01025823.

Camberlin, P., 2009: Nile basin climates. The Nile: Origin, Environments, Limnology and Human Use, H. J. Dumont, Ed. Springer, 307-333.

Carlson, T. N., and F. H. Ludlam, 1968: Conditions for the occurrence of severe local storms. Tellus, 20, 203-226, https:// doi.org/10.3402/tellusa.v20i2.10002.

_- , and J. M. Prospero, 1972: The large-scale movement of Saharan air outbreaks over the northern equatorial Atlantic. J. Appl. Meteor., 11, 283-297, https://doi.org/ 10.1175/1520-0450(1972)011<0283:TLSMOS>2.0.CO;2.

—, S. G. Benjamin, G. S. Forbes, and Y.-F. Li, 1983: Elevated mixed layers in the regional severe storm environment: Conceptual model and case studies. Mon. Wea. Rev., 111, 14531473, https://doi.org/10.1175/1520-0493(1983)111<1453: EMLITR $>2.0 . \mathrm{CO} ; 2$.

Carr, F. H., and J. P. Millard, 1985: A composite study of comma clouds and their association with severe weather over the
Great Plains. Mon. Wea. Rev., 113, 370-387, https://doi.org/ 10.1175/1520-0493(1985)113<0370:ACSOCC > 2.0.CO;2.

Cho, C., and D. H. Staelin, 2006: Cloud clearing of Atmospheric Infrared Sounder hyperspectral infrared radiances using stochastic methods. J. Geophys. Res., 111, D09S18, https:// doi.org/10.1029/2005JD006013.

Conzemius, R. J., and E. Fedorovich, 2006: Dynamics of sheared convective boundary layer entrainment. Part I: Methodological background and large-eddy simulations. J. Atmos. Sci., 63, 1151-1178, https://doi.org/10.1175/JAS3691.1.

Cuesta, J., and Coauthors, 2008: Multiplatform observations of the seasonal evolution of the Saharan atmospheric boundary layer in Tamanrasset, Algeria, in the framework of the African Monsoon Multidisciplinary Analysis field campaign conducted in 2006. J. Geophys. Res., 113, D00C07, https://doi.org/ 10.1029/2007JD009417.

— J. H. Marsham, D. J. Parker, and C. Flamant, 2009: Dynamical mechanisms controlling the vertical redistribution of dust and the thermodynamic structure of the West Saharan atmospheric boundary layer during summer. Atmos. Sci. Lett., 10, 34-42, https://doi.org/10.1002/asl.207.

Dee, D. P., and Coauthors, 2011: The ERA-Interim reanalysis: Configuration and performance of the data assimilation system. Quart. J. Roy. Meteor. Soc., 137, 553-597, https://doi.org/ 10.1002/qj.828.

Durre, I., R. S. Vose, and D. B. Wuertz, 2006: Overview of the Integrated Global Radiosonde Archive. J. Climate, 19, 53-68, https://doi.org/10.1175/JCLI3594.1.

Faccani, C., and Coauthors, 2009: The impacts of AMMA radiosonde data on the French global assimilation and forecast system. Wea. Forecasting, 24, 1268-1286, https://doi.org/10.1175/ 2009WAF2222237.1.

Fink, A. H., 2017: Mean climate and seasonal cycle. Meteorology of Tropical West Africa, D. J. Parker and M. Diop-Kane, Eds., Wiley Blackwell, 1-39.

—- and Coauthors, 2011: Operational meteorology in West Africa: Observational networks, weather analysis and forecasting. Atmos. Sci. Lett., 12, 135-141, https://doi.org/10.1002/asl.324.

Fitzpatrick, R. G. J., C. L. Bain, P. Knippertz, J. H. Marsham, and D. J. Parker, 2015: The West African monsoon onset: A concise comparison of definitions. J. Climate, 28, 8673-8694, https://doi.org/10.1175/JCLI-D-15-0265.1.

Flamant, C., J.-P. Chaboureau, D. J. Parker, C. M. Taylor, J.-P. Cammas, O. Bock, F. Timouk, and J. Pelon, 2007: Airborne observations of the impact of a convective system on the planetary boundary layer thermodynamics and aerosol distribution in the inter-tropical discontinuity region of the West African monsoon. Quart. J. Roy. Meteor. Soc., 133, 1175-1189, https://doi.org/10.1002/qj.97.

Gamo, M., 1996: Thickness of the dry convection and large-scale subsidence above deserts. Bound.-Layer Meteor., 79, 265-278, https://doi.org/10.1007/BF00119441.

Garcia-Carreras, L., and Coauthors, 2013: The impact of convective cold pool outflows on model biases in the Sahara. Geophys. Res. Lett., 40, 1647-1652, https://doi.org/10.1002/ grl.50239.

— and Coauthors, 2015: The turbulent structure and diurnal growth of the Saharan atmospheric boundary layer. J. Atmos. Sci., 72, 693-713, https://doi.org/10.1175/JAS-D-13-0384.1.

Gelaro, R., and Coauthors, 2017: The Modern-Era Retrospective Analysis for Research and Applications, version 2 (MERRA-2). J. Climate, 30, 5419-5454, https://doi.org/10.1175/JCLI-D16-0758.1. 
Gounou, A., F. Guichard, and F. Couvreux, 2012: Observations of diurnal cycles over a West African meridional transect: Premonsoon and full-monsoon seasons. Bound.-Layer Meteor., 144, 329-357, https://doi.org/10.1007/s10546-012-9723-8.

Graf, M. A., M. Sprenger, and R. W. Moore, 2011: Central European tornado environments as viewed from a potential vorticity and Lagrangian perspective. Atmos. Res., 101, 31-45, https://doi.org/10.1016/j.atmosres.2011.01.007.

Grundstein, A., M. Shepherd, P. Miller, and S. E. Sarnat, 2017: The role of mesoscale-convective processes in explaining the 21 November 2016 epidemic thunderstorm asthma event in Melbourne, Australia. J. Appl. Meteor. Climatol., 56, 13371343, https://doi.org/10.1175/JAMC-D-17-0027.1.

Honda, T., and T. Kawano, 2015: How does mid-tropospheric dry air affect the evolution of supercellular convection? Atmos. Res., 157, 1-16, https://doi.org/10.1016/j.atmosres.2015.01.015.

James, R. P., and P. M. Markowski, 2010: A numerical investigation of the effects of dry air aloft on deep convection. Mon. Wea. Rev., 138, 140-161, https://doi.org/ 10.1175/2009MWR3018.1.

Knippertz, P., 2003: Tropical-extratropical interactions causing precipitation in northwest Africa: Statistical analysis and seasonal variations. Mon. Wea. Rev., 131, 3069-3076, https:// doi.org/10.1175/1520-0493(2003)131<3069:TICPIN>2.0.CO;2. , and M. C. Todd, 2010: The central west Saharan dust hot spot and its relation to African easterly waves and extratropical disturbances. J. Geophys. Res., 115, D12117, https://doi.org/ 10.1029/2009JD012819.

—, M. Christoph, and P. Speth, 2003: Long-term precipitation variability in Morocco and the link to the large-scale circulation in recent and future climates. Meteor. Atmos. Phys., 83, 67-88, https://doi.org/10.1007/s00703-002-0561-y.

— , and Coauthors, 2009: Dust mobilization and transport in the northern Sahara during SAMUM 2006-A meteorological overview. Tellus, 61B, 12-31, https://doi.org/10.1111/j.16000889.2008.00380.x.

Lanicci, J. M., T. N. Carlson, and T. T. Warner, 1987: Sensitivity of the Great Plains severe-storm environment to soil-moisture distribution. Mon. Wea. Rev., 115, 2660-2673, https://doi.org/ 10.1175/1520-0493(1987)115<2660:SOTGPS $>2.0$. CO;2.

Lélé, M. I., and P. J. Lamb, 2010: Variability of the intertropical front (ITF) and rainfall over the West African Sudan-Sahel zone. J. Climate, 23, 3984-4004, https://doi.org/10.1175/ 2010JCLI3277.1.

Liu, N., and C. Liu, 2018: Synoptic environments and characteristics of convection reaching the tropopause over northeast China. Mon. Wea. Rev., 146, 745-759, https://doi.org/10.1175/ MWR-D-17-0245.1.

Lucas, C., E. J. Zipser, and B. S. Ferrier, 2000: Sensitivity of tropical West Pacific oceanic squall lines to tropospheric wind and moisture profiles. J. Atmos. Sci., 57, 2351-2373, https://doi.org/ 10.1175/1520-0469(2000)057<2351:SOTWPO>2.0.CO;2.

Ma, X. L., T. J. Schmit, and W. L. Smith, 1999: A nonlinear physical retrieval algorithm-Its application to the GOES-8/ 9 sounder. J. Appl. Meteor., 38, 501-513, https://doi.org/ 10.1175/1520-0450(1999)038<0501:ANPRAI >2.0.CO;2.

Marsham, J. H., D. J. Parker, C. M. Grams, B. T. Johnson, W. M. F. Grey, and A. N. Ross, 2008: Observations of mesoscale and boundary-layer scale circulations affecting dust transport and uplift over the Sahara. Atmos. Chem. Phys., 8, 6979-6993, https://doi.org/10.5194/acp-8-6979-2008.

, and Coauthors, 2013: Meteorology and dust in the central Sahara: Observations from Fennec supersite-1 during the June
2011 intensive observation period. J. Geophys. Res. Atmos., 118, 4069-4089, https://doi.org/10.1002/jgrd.50211.

, D. J. Parker, M. C. Todd, J. R. Banks, H. E. Brindley, L. Garcia-Carreras, A. J. Roberts, and C. L. Ryder, 2016: The contrasting roles of water and dust in controlling daily variations in radiative heating of the summertime Saharan heat low. Atmos. Chem. Phys., 16, 3563-3575, https://doi.org/ 10.5194/acp-16-3563-2016.

Matsangouras, I. T., P. T. Nastos, H. B. Bluestein, and M. V. Sioutas, 2014: A climatology of tornadic activity over Greece based on historical records. Int. J. Climatol., 34, 2538-2555, https://doi.org/10.1002/joc.3857.

Medina, S., R. A. Houze Jr., A. Kumar, and D. Niyogi, 2010: Summer monsoon convection in the Himalayan region: Terrain and land cover effects. Quart. J. Roy. Meteor. Soc., 136, 593-616, https://doi.org/10.1002/qj.601.

Menzel, W. P., T. J. Schmit, P. Zhang, and J. Li, 2018: Satellitebased Atmospheric Infrared Sounder development and applications. Bull. Amer. Meteor. Soc., 99, 583-603, https:// doi.org/10.1175/BAMS-D-16-0293.1.

Messager, C., D. J. Parker, O. Reitebuch, A. Agusti-Panareda, C. M. Taylor, and J. Cuesta, 2010: Structure and dynamics of the Saharan atmospheric boundary layer during the West African monsoon onset: Observations and analyses from the research flights of 14 and 17 July 2006. Quart. J. Roy. Meteor. Soc., 136, 107-124, https://doi.org/10.1002/qj.469.

Milstein, A. B., and W. J. Blackwell, 2016: Neural network temperature and moisture retrieval algorithm validation for AIRS/AMSU and CrIS/ATMS. J. Geophys. Res. Atmos., 121, 1414-1430, https://doi.org/10.1002/2015JD024008.

Moeng, C.-H., and P. P. Sullivan, 1994: A comparison of shear- and buoyancy-driven planetary boundary layer flows. J. Atmos. Sci., 51, 999-1022, https://doi.org/10.1175/1520-0469(1994) $051<0999: \mathrm{ACOSAB}>2.0 . \mathrm{CO} ; 2$

Nicholls, S. D., and K. I. Mohr, 2010: An analysis of the prestorm environment of intense West African convective systems. Mon. Wea. Rev., 138, 3721-3739, https://doi.org/ 10.1175/2010MWR3321.1.

Nicholson, S. E., 1996: A review of climate dynamics and climate variability in eastern Africa. Limnology, Climatology and Paleoclimatology of the East African Lakes, T. C. Johnson and E. O. Odada, Eds., CRC Press, 25-56.

- 2011: Dryland Climatology. Cambridge University Press, 516 pp. Office of the Federal Coordinator of Meteorology, 1997: Rawinsonde and pibal observations. National Oceanographic and Atmospheric Administration Rep. FCM-H3-1997, 191 pp.

Parker, D. J., and Coauthors, 2005: The diurnal cycle of the West African monsoon circulation. Quart.J. Roy. Meteor. Soc., 131, 2839-2860, https://doi.org/10.1256/qj.04.52.

Parkinson, C. L., 2003: Aqua: An Earth-observing satellite mission to examine water and other climate variables. IEEE Trans. Geosci. Remote Sens., 41, 173-183, https://doi.org/10.1109/ TGRS.2002.808319.

Peckham, S. E., R. B. Wilhelmson, L. J. Wicker, and C. L. Ziegler, 2004: Numerical simulation of the interaction between the dryline and horizontal convective rolls. Mon. Wea. Rev., 132, 1792-1812, https://doi.org/10.1175/1520-0493(2004)132<1792: NSOTIB $>2.0 . \mathrm{CO} ; 2$.

Prospero, M. J., and T. N. Carlson, 1981: Saharan air outbreaks over the tropical North Atlantic. Pure Appl. Geophys., 119, 677-691, https://doi.org/10.1007/BF00878167.

Púčik, T., P. Groenemeijer, D. Rýva, and M. Kolář, 2015: Proximity soundings of severe and nonsevere thunderstorms 
in central Europe. Mon. Wea. Rev., 143, 4805-4821, https:// doi.org/10.1175/MWR-D-15-0104.1.

Rasmussen, K. L., and R. A. Houze Jr., 2011: Orogenic convection in subtropical South America as seen by the TRMM satellite. Mon. Wea. Rev., 139, 2399-2420, https://doi.org/10.1175/ MWR-D-10-05006.1.

Raveh-Rubin, S., 2017: Dry intrusions: Lagrangian climatology and dynamical impact on the planetary boundary layer. J. Climate, 30, 6661-6682, https://doi.org/10.1175/JCLI-D-16-0782.1.

Reale, O., E. L. McGrath-Spangler, W. McCarty, D. Holdaway, and R. Gelaro, 2018: Impact of adaptively thinned AIRS cloud-cleared radiances on tropical cyclone representation in a global data assimilation and forecast system. Wea. Forecasting, 33, 909-931, https://doi.org/10.1175/WAF-D-17-0175.1.

Roberts, A. J., J. H. Marsham, and P. Knippertz, 2015: Disagreements in low-level moisture between (re)analyses over summertime West Africa. Mon. Wea. Rev., 143, 1193-1211, https:// doi.org/10.1175/MWR-D-14-00218.1.

Roca, R., J.-P. Lafore, C. Piriou, and J.-L. Redelsperger, 2005: Extratropical dry-air intrusions into the West African monsoon midtroposphere: An important factor for the convective activity over the Sahel. J. Atmos. Sci., 62, 390-407, https://doi.org/10.1175/JAS-3366.1.

Romatschke, U., and R. A. Houze Jr., 2011: Characteristics of precipitating convective systems in the premonsoon season of South Asia. J. Hydrometeor., 12, 157-180, https://doi.org/ 10.1175/2010JHM1311.1.

__ , S. Medina, and R. A. Houze Jr., 2010: Regional, seasonal, and diurnal variations of extreme convection in the South Asian region. J. Climate, 23, 419-439, https://doi.org/10.1175/ 2009JCLI3140.1.

Schaefer, J. T., 1974: The life cycle of the dryline. J. Appl. Meteor., 13, 444-449, https://doi.org/10.1175/1520-0450(1974) $013<0444$ :TLCOTD $>2.0$. CO;2.

Stubenrauch, C. J., A. G. Feofilov, S. E. Protopapadaki, and R. Armante, 2017: Cloud climatologies from the infrared sounders AIRS and IASI: Strengths and applications. Atmos. Chem. Phys., 17, 13 625-13 644, https://doi.org/10.5194/acp-1713625-2017.

Susskind, J., J. Blaisdell, and L. Iredell, 2012: Significant advances in the AIRS Science Team version-6 retrieval algorithm. Proc. SPIE, 8510, 85100U, https://doi.org/10.1117/12.929953.

, — _ and — , 2014: Improved methodology for surface and atmospheric soundings, error estimates, and quality control procedures: The Atmospheric Infrared Sounder Science Team version-6 retrieval algorithm. J. Appl. Remote Sens., 8, 084994, https://doi.org/10.1117/1.JRS.8.084994.
Takemi, T., 2014: Convection and precipitation under various stability and shear conditions: Squall lines in tropical versus midlatitude environment. Atmos. Res., 142, 111-123, https:// doi.org/10.1016/j.atmosres.2013.07.010.

Trier, S. B., G. S. Romine, D. A. Ahijevych, R. J. Trapp, R. S. Schumacher, M. C. Coniglio, and D. J. Stensrud, 2015: Mesoscale thermodynamic influences on convection initiation near a surface dryline in a convection-permitting ensemble. Mon. Wea. Rev., 143, 3726-3753, https://doi.org/10.1175/ MWR-D-15-0133.1.

Vergados, P., A. J. Mannucci, C. O. Ao, O. Verkhoglyadova, and B. Iijima, 2018: Comparisons of the tropospheric specific humidity from GPS radio occultations with ERA-Interim, NASA MERRA, and AIRS data. Atmos. Meas. Tech., 11, 1193-1206, https://doi.org/10.5194/amt-11-1193-2018.

Vizy, E. K., and K. H. Cook, 2009: A mechanism for African monsoon breaks: Mediterranean cold air surges. J. Geophys. Res., 114, D01104, https://doi.org/10.1029/2008JD010654.

_ , and -2018: Mesoscale convective systems and nocturnal rainfall over the West African Sahel: Role of the inter-tropical front. Climate Dyn., 50, 587-614, https://doi.org/10.1007/ s00382-017-3628-7.

Wahab, M. A., M. El-Metwally, R. Hassan, M. Lefèvre, A. Oumbe, and L. Wald, 2010: Assessing surface solar irradiance and its long-term variations in the northern Africa desert climate using Meteosat images. Int. J. Remote Sens., 31, 261-280, https://doi.org/10.1080/01431160902882645.

Wang, S., and A. H. Sobel, 2012: Impact of imposed drying on deep convection in a cloud-resolving model. J. Geophys. Res., 117, D02112, https://doi.org/10.1029/2011JD016847.

Warner, T. T., 2004: Desert Meteorology. Cambridge University Press, $595 \mathrm{pp}$.

Weng, F., L. Zhao, R. R. Ferraro, G. Poe, X. Li, and N. C. Grody, 2003: Advanced Microwave Sounding Unit cloud and precipitation algorithms. Radio Sci., 38, 8068, https://doi.org/ 10.1029/2002RS002679.

Yamane, Y., T. Hayashi, M. Kiguchi, F. Akter, and A. M. Dewan, 2013: Synoptic situations of severe local convective storms during the pre-monsoon season in Bangladesh. Int. J. Climatol., 33, 725-734, https://doi.org/10.1002/joc.3460.

Zhang, C., and J. Pennington, 2004: African dry air outbreaks. J. Geophys. Res., 109, D20108, https://doi.org/10.1029/ 2003JD003978.

Zuluaga, M. D., and R. A. Houze Jr., 2015: Extreme convection of the near-equatorial Americas, Africa, and adjoining oceans as seen by TRMM. Mon. Wea. Rev., 143, 298-316, https://doi.org/ 10.1175/MWR-D-14-00109.1. 